Published in final edited form as:

Woodhead Publ Ser Biomater. 2013 ; 2013: 105-150. doi:10.1533/9780857093516.2.105.

\title{
Nanostructured diamond coatings for orthopaedic applications
}

\author{
S.A. CATLEDGE, V. THOMAS, and Y.K. VOHRA \\ University of Alabama at Birmingham, USA
}

\begin{abstract}
With increasing numbers of orthopaedic devices being implanted, greater emphasis is being placed on ceramic coating technology to reduce friction and wear in mating total joint replacement components, in order to improve implant function and increase device lifespan. In this chapter, we consider ultra-hard carbon coatings, with emphasis on nanostructured diamond, as alternative bearing surfaces for metallic components. Such coatings have great potential for use in biomedical implants as a result of their extreme hardness, wear resistance, low friction and biocompatibility. These ultra-hard carbon coatings can be deposited by several techniques resulting in a wide variety of structures and properties.
\end{abstract}

\section{Keywords}

orthopaedic implant; nanostructured diamond coating; ultra-hard carbon; wear; biocompatibility

\subsection{Introduction}

Orthopaedic surgery or orthopaedics is the branch of surgery concerned with conditions involving the musculoskeletal system. Orthopaedic surgeons use both surgical and nonsurgical means to treat musculoskeletal trauma, sports injuries, degenerative diseases, infections, tumours and congenital disorders. Modern total hip replacement was pioneered by Sir John Charnley in the 1960s (Wroblewski, 2002). He found that joint surfaces could be replaced by metal or high density polyethylene implants cemented to the bone with methyl methacrylate bone cement. Since Charnley, there have been many improvements in the design of joint replacement (arthroplasty), including the development of uncemented arthroplasty techniques with the bone bonding directly to the implant. Recently, surface replacement of joints, especially the hip joint, has become more popular in younger and more active patients. This type of operation delays the need for the more traditional and less bone-conserving total hip replacement, but carries significant risks of early failure from fracture and bone death.

Despite all the innovations made with joint replacements over the years, wear of the bearing surfaces of components remains a substantial problem. Wear can lead to damage to surrounding bone and contribute to eventual failure of the implant. Use of alternative bearing surfaces has increased in recent years in an attempt to minimize wear debris of joint replacement components. These include ceramics and all-metal implants (as opposed to the more common metal-on-polyethylene). The polyethylene is traditionally of ultra-high molecular weight and can be modified in ways that may improve wear characteristics. 
Motivated by the extreme hardness of diamond and other ultra-hard carbon materials and the need for reducing wear in articulating implant devices, alternative bearing surfaces are actively being investigated. These technologies must undergo critical assessment in terms of their viability as being robust and more effective than the current state-of-the-art.

\subsubsection{Limitations of current orthopaedic implant designs}

Statistics from the American Academy of Orthopaedic Surgeons show that more than 418,000 total and partial knee replacements are performed each year, $15 \%$ of them on baby boomers; of the 328,000 total and partial hip replacements done, boomers are the recipients of more than $20 \%$. According to a study presented at the 73rd annual meeting of the American Academy of Orthopaedic Surgery in Chicago (Kurtz et al., 2006), the number of total knee replacements and total hip replacements performed in the USA will leap by $673 \%$ and $174 \%$, respectively, by the year 2030 . The new projections suggest that the number of revision surgeries will double by 2015 for total knee replacements, and that hip replacement revisions will double by 2026. Other joints, such as shoulders, elbows and temporomandibular joints are also routinely replaced. Despite improvements in surgical technique and in the designs of prostheses, revision rates do not seem to be declining over time. Revision surgery is much more complex a surgical procedure then the primary joint replacement. It is a longer, more complicated, technically demanding surgery, where optimal positioning and fixation of the prosthesis is a real challenge. With revision joint replacement surgery, the recovery is also longer, with more of a toll on the patient, and even a higher complication rate.

The apparent critical need to reduce the number of revision surgeries motivates a firm understanding of what causes initial implants to fail over time. A primary cause of failure is the generation of wear debris particles at the articulating surface that causes local pain and inflammation. Wear of articulating surfaces involving Co-Cr-Mo alloy-on-polyethylene (used in the majority of hip and knee arthroplasties) has been cited as a dominant factor limiting the long-term success of the implant (Amstutz et al., 1992, Goldring et al., 1983). An ongoing concern in conventional total joint replacement prostheses is osteolysis and aseptic loosening induced by wear debris originating from the interfaces of articulating components. Wear can lead to component loosening, deleterious biological responses, osteolysis (bone loss), mechanical instability, decreased joint mobility, increased pain and, ultimately, implant failure (Mercuri, 2000a). Large debris pieces are normally sequestered by fibrous tissue, whereas small debris is taken up by macrophages and multinucleated giant cells which may release cytokines that result in inflammation. This inflammation cascade damages surrounding bone, ultimately resulting in osteolysis. The inflammatory response also leads to the recruitment of activated osteoclasts at the bone-implant interface. This tissue death around the implant can eventually result in loosening and implant failure. One solution for this problem of osteolysis caused by wear debris is to develop harder materials for the articulating surfaces that are more wear resistant, which would reduce the number and size of debris particles generated. In early total joint arthroplasty systems, metal-onmetal articulating materials were selected. Cast cobalt alloy metal-on-metal components were used for temporomandibular arthroplasty and exhibited resistance to fretting and wear. Orthopaedic research (Amstutz and Grigoris, 1996, McKellop et al., 1996, Medley et al., 
1996) has revealed that much less wear occurs with metal-on-metal hip prosthesis, up to 100 times less than that of polyethylene-on-metal. Unfortunately, there continue to be concerns associated with metal sensitivity and metallosis, the release of alloy constituents into the surrounding tissue. The term 'metallosis' has also been used to describe the intraoperative findings of gross metallic debris and blackening of periprosthetic tissue (McGovern and Moskal, 2002). Metal sensitivity, which affects approximately 10-15\% of the general population, is much higher among patients with failed implants (Wagner and Wagner, 2000, Hallab et al., 2001, Moran and Tourret, 2001).

In most commercial joint prostheses in use today, a polished metallic CoCrMo surface articulates with a much softer polyethylene surface. The rationale is that with this set-up, almost all of the debris generated will be the softer and relatively less toxic polyethylene debris. This approach effectively reduces the production of toxic metallic ions; however, even in ideal conditions, the wear rate of the polyethylene cup in a hip implant is expected to be 0.1-0.2 mm/year (National Institutes of Health, 1994). Dividing the thickness of the cup by this wear rate will give the maximum expected life, but there are many instances where scratches on the CoCrMo surface cause acceleration of this wear rate. Sources of scratches that commonly cause scratches on CoCrMo condyles originate from bone, bone cement, prosthetic coatings for bone ingrowth (especially titanium beads), wear and corrosion products from modular junctions, and metallic transfer from metal liner following a dislocation. When hard, third-body particles roughen the metal femoral component, it leads to scratches and increased abrasive wear of the softer poly counterface. Surfaces that are more resistant to abrasive scratching reduce the potential for abrasive wear. Now that implants are routinely reaching near the maximum life expectancy, requiring surgery to replace the polyethylene cup, a more permanent solution to minimize wear debris is needed.

The goal of minimizing polyethylene wear debris (or eliminating it altogether) has led to renewed interest in ceramic articulation components, and, with recent improvements in manufacturing and prosthetic designs, ceramic materials are performing much better than in their initial clinical uses in the 1970s. In addition to using metal-on-metal designs, current trends in orthopaedic implant design involve developing ceramic surface components such as oxidized zirconium or nitrided titanium (Fig. 5.1) (Lombardi et al., 2004, Cuckler, 2005, Bal et al., 2005). Titanium nitride (TiN) coatings on cp-Ti and Ti-6Al-4V alloy demonstrated reduced wear rates in hip simulator studies (Gutmanas and Gotman, 2004). TiN coatings deposited from cathodic arc physical vapour deposition techniques were shown to reduce fretting behaviour of untreated Ti-6Al-4V surfaces (Hendry and Pilliar, 2001). Oxidized zirconium, featuring a 3-5 $\mu \mathrm{m}$ thick diffused oxide layer on the surface of zirconium metal, has been associated with reduced wear rates when coupled with ultrahigh molecular weight (UHMW) polyethylene components (Good et al., 2003, 2005). Short-term clinical success of oxidized zirconium in total knee arthroplasty has also been reported (Innocenti et al., 2010). The rationale for this approach is that by employing materials with much greater hardness, the generation of wear debris can be minimized. Similarly, data of annual linear wear rates for several orthopaedic couplings show that volumetric wear for alumina-alumina couplings $(0.002 \mathrm{~mm} / \mathrm{year})$ is much lower than for alumina-polyethylene (0.05-0.1 mm/year) or cobalt chrome-polyethylene (0.1-0.4 mm/year) couplings (Catledge 
et al., 2005). The benefits of ceramics for orthopaedic implant surfaces are becoming increasingly evident due to their outstanding mechanical and biocompatibility properties. There is also strong evidence showing that many nanostructured ceramics exhibit improved mechanical properties (such as hardness, ductility, and enhanced strain to failure) over their conventional larger-grained counterparts (Bohn et al., 1991, Mayo et al., 1990, 1992).

\subsubsection{Joint resurfacing alternatives}

Joint resurfacing may be considered an alternative to total joint arthroplasty, particularly in young active patients who would potentially outlive a total hip or knee prosthesis. Therefore, total hip resurfacing could be viewed as a time-buying procedure to delay the need for a total hip arthroplasty. For example, proposed advantages of total hip resurfacing compared to total hip arthroplasty include preservation of the femoral neck and femoral canal, thus facilitating revision or conversion to a total hip replacement, if required (Amstutz et al., 2004, Beaule et al., 2004). In May 2006 the FDA granted premarket application (PMA) approval to the metal-on-metal Birmingham Hip Resurfacing (BHR) System (Smith and Nephew, Inc.) for use in patients requiring primary hip arthroplasty for non-inflammatory or inflammatory arthritis. The BHR uses femoral and acetabular components made of high carbon cobalt-chromium alloy. Metal-on-metal total hip resurfacing with a fully FDA approved total hip resurfacing device may be considered medically necessary when the patient is likely to outlive a traditional prosthesis and would otherwise require a total hip replacement. The FDA lists several contraindications for total hip resurfacing. These contraindications include: bone stock inadequate to support the device, skeletal immaturity, vascular insufficiency, muscular atrophy, or neuromuscular disease severe enough to compromise implant stability or postoperative recovery, known moderate to severe renal insufficiency, severely overweight, known or suspected metal sensitivity, immunosuppressed or receiving high doses of corticosteroids.

Some outcomes have been reported with the BHR device suggesting medium to long-term durability. Treacy and colleagues reported that the 5-year survival of BHR arthroplasty in 144 patients was 98\% overall (Treacy et al., 2005). Shimmin and Back reviewed 3497 BHRs performed by 89 surgeons between April 1999 and April 2004 (Shimmin and Back, 2005). The authors reported that the incidence of femoral neck fracture was $1.46 \%$ (50 of 3497 ) and the mean time to fracture was 15.4 weeks. Glyn-Jones and colleagues evaluated the stability of BHR arthroplasties by radiographic analysis in 22 hips in 20 patients (GlynJones et al., 2004). At 24 months, migration of the head of the femoral component was not statistically significant ( $0.2 \mathrm{~mm}$ total three-dimensional). A substantial body of evidence shows that total hip resurfacing is associated with consistent and strong symptomatic and functional improvements comparable to those obtained with current total hip arthroplasty (THA) in patients less than 65 years old. The available evidence shows that the short-term symptomatic and functional health benefits of HR are at least as good as those of THA over midterm follow-up, with no substantial differences in revision rates, among patients younger than 65 years who are likely to outlive a traditional prosthesis. Also, inference from the available long-term evidence suggests that HR will be at least as beneficial as THA in patients who are likely to outlive a traditional prosthesis. 
Despite the apparent benefits of joint resurfacing over total joint arthroplasty, a limitation of hip resurfacing is that the bearing is a cobalt-chrome alloy surface gliding against another cobalt-chrome surface. Although the wear rates of such metal-on-metal bearings are low, this technology has some potential concerns. Very rarely, a patient with a metal-on-metal bearing can develop a metal hypersensitivity reaction. Also, hip resurfacing is not recommended for women of child-bearing age and in patients with decreased kidney function. In both groups, it is speculated that the possible toxicity of metal particles could lead to future problems. With regards to long-term safety, literature summaries provided to the FDA demonstrated increased serum and urinary concentrations of metal ions postoperatively in patients, particularly after metal-on-metal procedures, although data show no conclusive evidence of significant detrimental effects (ASTM_F732-00, 2003).

\subsection{Ultra-hard carbon coatings}

Highly crystalline chemical vapour deposition (CVD) diamond is often considered as a wear-resistant material for applications such as cutting tools. However, its extreme properties, including hardness close to $100 \mathrm{GPa}$, are not easily exploited due to its inherently brittle nature and high surface roughness. Conventional diamond films synthesized by the vapour phase exhibit columnar crystal growth; once cracks occur on the surface of the film, they tend to propagate through the columnar particles, leading to a decrease in film and interface toughness. A number of deposition techniques have been utilized to produce several variants of carbon structures, distinguished primarily by the nature of carbon bonding ( $\mathrm{sp}^{3} \mathrm{vs} \mathrm{sp}^{2}$ hybridized) and the degree of order (crystalline vs amorphous), as well as by the degree to which hydrogen is incorporated into the structure. The $\mathrm{sp}^{3}$ bonds can occur not only within crystals (i.e. with long-range order), but also within amorphous solids where the atoms are in a random arrangement. The bond types have a considerable influence on the material properties of carbon films. If the $\mathrm{sp}^{2}$ type is predominant the film will be softer, if the $\mathrm{sp}^{3}$ type is predominant the film will be harder. In addition to the various forms of purely amorphous carbon, designated as 'diamond-like carbon' (DLC), phase-pure 'nanocrystalline diamond' (NCD) with grain sizes of 30-100 nm and 'ultra-nanocrystalline diamond' (UNCD) (Shenderova and Gruen, 2006) with grain sizes as low as 3-5 nm have been developed for several applications. Yet another carbon structure has been associated with composite-like characteristics associated with nanocrystalline diamond grains imbedded within an amorphous carbon matrix, designated as 'nanostructured diamond' (NSD) or 'ultra-smooth nanostructured diamond' (USND) (Konovalov et al., 2006), depending on the size of diamond grains (as low as $5-6 \mathrm{~nm}$ ). Of the various carbon structures reported, only DLC and NSD/USND coatings have been extensively investigated for wear-resistant articulating components in dental and orthopaedic devices.

\subsubsection{Diamond-like carbon coatings for orthopaedic implants}

DLC is a purely amorphous carbon material with varying amounts of $\mathrm{sp}^{3}$ bonding and has been investigated for use in medical applications as a result of its excellent wear properties and biocompatibility (Roy and Lee, 2007, Narayan, 2005). Hydrogen-containing amorphous carbon (a-C:H), amorphous carbon without hydrogen (a-C) and pure $\mathrm{sp}^{3}$-hybridized amorphous carbon (ta-C) are typical forms, each with potentially different mechanical 
properties. Vickers hardness for a-C and a-C:H are typically between 1500 and $3500 \mathrm{HV}$ and up to $\sim 40 \% \mathrm{sp}^{3}$, whereas tetrahedral amorphous carbon (ta-C) can have 4000-9000HV with $80-85 \% \mathrm{sp}^{3}$. Raman spectroscopy has been a valuable tool in characterizing these coatings for predicting structure, optical and mechanical properties.(Ferrari and Robertson, 1999, Tamor and Vassell, 1994) Traditionally, the largest inherent problem with DLC coatings has been issues of residual stress; higher $\mathrm{sp}^{3}$ contents lead to a harder coating but at the expense of higher compressive stress (Morshed et al., 2003, Schwan, 1997). The internal compressive stress in DLC coatings can be as high as $10 \mathrm{GPa}$, which dramatically limits coating thickness. Such stresses can create unstable interfaces (i.e. adhesion and/or cohesion issues) and the film may become prone to delamination. It has been shown that for the case of ultra-hard ta-C coatings thermal annealing at $\sim 650^{\circ} \mathrm{C}$ can dramatically reduce the large compressive stress to near zero without substantial change in $\mathrm{sp}^{3}$ bonding (Grierson $e$ t al., 2010, Friedmann et al., 1997).

Although DLC in its various forms is widely studied, issues regarding instability of the coating caused by high levels of residual stress and poor adhesion in aqueous environments remain of concern. For a thorough review of DLC coatings for biomedical applications, the reader is referred to the comprehensive work by Roy and Lee (Roy and Lee, 2007).

\subsubsection{Nanostructured diamond coatings for orthopaedic implants}

Another potential coating system to address the issues associated with wear and metal ion release in orthopaedic and dental implants is that of ultra-smooth nanostructured diamond (NSD and USND) coatings. These have been developed for metal implant surfaces including titanium and cobalt-based alloys using microwave plasma CVD (Catledge et al., 2011, Catledge and Vohra, 1999, Chowdhury et al., 2008). The NSD coatings could prove to be more resistant to scratching by third body wear particles, such as bone cement, due to the high hardness (56-80 GPa) and low surface roughness (rms value $<10 \mathrm{~nm}$ ) of the coatings (Papo et al., 2004, Konovalov et al., 2006, Chowdhury, 2006, Catledge et al., 2002). They have been characterized as a mixture of $\mathrm{sp}^{3}$ and $\mathrm{sp}^{2}$ bonded carbon, with nanometre sized diamond particles embedded in an amorphous carbon matrix. They combine high hardness, low surface roughness, and excellent fracture toughness and adhesion, especially to titanium alloys.

The inherent challenges in successfully coating NSD onto a metal substrate by CVD methods have been largely overcome for titanium and Ti-6Al-4V alloy substrates. By nature of the ultra-hard, yet somewhat compliant NSD coating and the strong interfacial carbide that naturally forms during deposition onto titanium surfaces, coating adhesion and tribological properties are excellent (Hill et al., 2008, Catledge and Vohra 2004, Catledge, 1995, Booth et al., 2011). A more difficult challenge faces NSD coating of cobaltchromium ( $\mathrm{CoCr}$ ) alloys that are so widely used as wear bearings in the orthopedic industry. The high cobalt content of this alloy acts as a catalyst for graphite that inevitably forms as an interfacial layer (Lawson et al., 2005). Such is the case for other transition metals of iron or nickel that have such high solubility for carbon. The formation of interfacial graphitic carbon and the lack of strongly bonded interfacial carbides is believed to be responsible for the poor coating quality and adhesion to this material. However, recently it was shown 
(Catledge et al., 2011) that use of oxygen in the feedgas can promote early formation of chromium oxides that act as an effective diffusion barrier to cobalt and therefore minimize interfacial graphite. These chromium oxides combined with chromium carbides that form at elevated substrate temperature are believed to be important interfacial phases that have led to improved adhesion of NSD coatings on CoCr orthopaedic alloys.

Nanostructured diamond on cobalt-chromium substrates-Cobalt-chromium alloys are widely used as the bearing surfaces in orthopaedic implants such as needed in total hip and knee replacement surgeries, because of their superior mechanical properties and resistance to corrosion and biodegradation (Black, 1992). Wear of articulating surfaces involving $\mathrm{CoCr}$ alloy-on-polyethylene (used in the majority of hip and knee arthroplasties) has been cited as a dominant factor limiting the long-term success of the implant (Amstutz et al., 1992, Goldring et al., 1983). Diamond coatings have been considered for these alloys in order to reduce the problems associated with wear and metal ion release, thereby increasing the lifetime of the implant in the body. Smooth NSD coatings would be expected to reduce friction and wear, which are the primary sources of failure in current orthopaedic implant devices. In addition, the diamond coating may act to prevent or slow the release of potentially toxic heavy metal ions into surrounding tissue from the alloy itself (Kobayashi $e t$ al., 2007, Ohgoe et al., 2006). However, CVD diamond deposition onto transition metals such as nickel and cobalt which have partially filled d-electron shells is made difficult because of the catalytic formation of graphite (Lettington and Steeds, 1994, Davis, 1993, Chen and Narayan, 1993) during initial stages of growth. These transition metals have high carbon diffusivity and do not form stable carbides, making nucleation of the diamond phase difficult. Once a graphitic layer is formed, the adhesion of a subsequently formed diamond layer is very weak. Several attempts have been made to improve diamond nucleation and adhesion using interlayers (Godbole et al., 1999, Wei et al., 2009, Polini et al., 2007, Zuo et al., 2003) to act as a buffer to limit carbon exposure to the substrate, by using laser irradiation to partially melt the substrate surface and react molten metal with carbon (Narayan et al., 1991), or by using C+ ion implantation (Lee et al., 1992). These approaches often involve an extra processing step and have yielded limited success.

One particularly promising method of CVD diamond deposition developed by Godbole et al. (Godbole et al., 1999) used a composite approach by sequential deposition of aluminium nitride with diamond followed by titanium carbide with diamond, as shown schematically in Fig. 5.2. The titanium carbide component, although found to be a very stable and effective barrier to the diffusion of cobalt, was not useful as a stand-alone buffer layer due to excessive thermally induced stress with consequent film cracking. However, the composite consists of randomly interconnected micron sized diamond crystallites, which are primarily surrounded by buffer material ( $\mathrm{AlN}$ or $\mathrm{TiC}$ ), whereas the contact area between neighbouring diamond crystallites is minimum. The presence of such a discontinuous morphology of diamond crystallites renders more toughness and also leads to compensation of stresses in localized regions (local stress management) and thus reduces bulging and subsequent delamination effects. Although the surface of the diamond coating is not nanostructured and therefore appears rough and faceted on a micron-scale, the method demonstrates the 
potential for reducing graphite formation and subsequent coating delamination that is so problematic for this alloy.

In light of the need for a single-step CVD process resulting in improved adhesion of ultrahard and smooth NSD coatings on CoCr alloy, Catledge et al. report the use of oxygen in a feedgas mixture containing hydrogen along with high methane content (up to $15 \mathrm{vol} \%$ ). It has been shown that one of the key roles of oxygen atoms in CVD diamond film growth is the $\mathrm{sp}^{2}$-sp ${ }^{3}$ conversion of C-C bonds on the surface.(Dementjev and Petukhov, 1998) However, its influence on interfacial structure/composition and diffusion of Co for growth of hard carbon films on CoCr substrates is not well studied. It was demonstrated that when oxygen is added to the $\mathrm{H}_{2} / \mathrm{CH}_{4}$ feedgas mixture for growth of NSD on CoCr alloy, the deleterious interaction of cobalt with carbon can be minimized through formation of an interfacial chromium oxide layer that effectively acts as a diffusion barrier to cobalt. Figure 5.3 shows the dramatic influence that oxygen has during the diamond nucleation and initial growth stages (before the coating has a chance to fully coalesce) through analysis of x-ray photoelectron spectroscopy (XPS) survey scans of the incomplete coatings, grown with and without use of oxygen. The most striking observation from these spectra is the absence of surface cobalt and molybdenum when oxygen is used in the feedgas. However, surface chromium is present and, as expected, a more intense oxygen peak is detected when oxygen feedgas is used. The $\mathrm{Co} / \mathrm{Cr}$ and $\mathrm{Co} / \mathrm{C}$ atomic ratios drop two orders of magnitude when oxygen is used and, as expected, the $\mathrm{O} / \mathrm{Cr}$ and $\mathrm{O} / \mathrm{Co}$ increase dramatically. High resolution spectra for Co 2p and Cr 2p, shown in Fig. 5.4, demonstrate the nature of bonding with oxygen for these metals in the early terminated films. Whereas no cobalt was detected when oxygen was used, without the use of oxygen Co $2 p$ spectra show a primary component of elemental cobalt with some bonding as cobalt oxide and cobalt hydroxide. The $\mathrm{Cr} 2 \mathrm{p}$ spectra also show a primarily elemental chromium component when oxygen is not used, along with chromium oxide. However, when oxygen is used, the chromium forms an oxide with essentially no elemental chromium remaining.

It was found that NSD coatings grown with oxygen on CoCrMo at substrate temperature in the range of $915-970^{\circ} \mathrm{C}$ show excellent adhesion, whereas those grown at lower temperatures or without oxygen delaminate. Despite the expected increase of thermally induced stress at the elevated temperature, improved adhesion of these coatings is attributed to a combined effect: higher interfacial chromium carbide content (observed at higher temperature) and reduced cobalt migration into the growing film (observed when oxygen is used). In contrast, the films grown at lower temperature (even in the presence of oxygen) show the presence of carbon nanotubes (Fig. 5.5) at the interface side of delaminated films, indicative of cobalt interaction with carbon. One might suggest that an interfacial carbide layer may itself be sufficient to act as a diffusion barrier to elemental cobalt. However, substantial graphitic soot is formed and adhesion is poor when oxygen is not used, even at the higher temperatures. Therefore, oxygen plays an important role in achieving soot-free, adhered diamond films on CoCrMo, particularly for the substrate temperature range of 915$970^{\circ} \mathrm{C}$. Overall, these results provide hope for successful coating of CoCrMo orthopaedic implant materials for improved joint performance and lifetime. Artificial joints involving 
diamond-on-diamond articulation may be a viable option leading to fewer and less invasive surgeries while maintaining high performance of the joint.

Nanostructured diamond on titanium substrates-CVD diamond on titanium and the biomedical alloy Ti-6Al-4V has been explored by numerous researchers (Scardi et al., 1997, Perry, 1993, Ager and Drory, 1993, Askari et al., 2008, Azevedo et al., 2005, Baek et al., 2003, Buccioni et al., 1999, Fu et al., 2003, Terranova, 1996). Issues deemed to be particularly important in this system include the potential hydrogen embrittlement of titanium, the large thermally induced residual stress in the diamond coating, relative amounts of interfacial titanium carbide, titanium hydride, and titanium oxide phases, and plastic flow of the substrate. Despite large residual stress in CVD diamond coatings on titanium substrates, as much as $7-8 \mathrm{GPa}$, the coating adhesion can be quite good, in large part because of the strongly bonded interfacial titanium carbide (Drory and Hutchinson, 1994, Vandenbulcke, 1998). Stress relaxation is influenced by tensile stress in the substrate (to offset compressive stress in the coating and interface), the thickness of the interfacial carbide and the nature of the diamond film itself.

The present authors have extensive experience in the deposition of NSD on Ti-6Al-4V alloy and have demonstrated exceptional coating adhesion while maintaining very low surface roughness and ultra-high hardness. Well-adherent NSD coatings on Ti-6Al-4V substrates synthesized by microwave plasma CVD with feedgas consisting of high methane (15 vol\%), hydrogen and nitrogen have been previously established (Toprani et al., 2000, Catledge, 1999). Based on these deposition conditions, the coatings feature low surface roughness (14-30 nm) and high hardness (70-90 GPa). Additionally, USND coatings synthesized with helium-rich plasmas were shown to further reduce grain size $(5-6 \mathrm{~nm})$ and surface roughness (9-10 nm), while maintaining high hardness in the range of 56-72 GPa (Chowdhury et al., 2006). These coatings may be described as a mixture of $\mathrm{sp}^{3}$ and $\mathrm{sp}^{2}$ bonded carbon, with nanometre sized diamond particles embedded in an amorphous carbon matrix.

Conventional micro-crystalline diamond films contain large micron size facets and are too rough to be used for implant components requiring low friction and minimal wear during articulation. The addition of $\mathrm{N}_{2}$ into the feedgas mixture (Jin, 1994) results in substantial changes in film morphology, structure and mechanical properties, and can lead to NSD as shown in Fig. 5.6 (Catledge, 1998, 1999, Chowdhury et al., 2008) In situ plasma diagnostics involving optical emission spectroscopy (OES) as well as thermodynamic equilibrium calculations to model the gas phase composition, revealed that the $\mathrm{CN}$ radical concentration in the plasma was an important parameter involved in the transformation from rough microcrystalline to smooth NSD films (Corvin, 2002). The NSD coating fracture toughness was also found to improve as a result of the addition of $\mathrm{N}_{2}$ to the feedgas (Toprani et al., 2000). Upon bulk indentation with a Rockwell indenter, films were observed to undergo significant plastic deformation without hard elastic-to-brittle fracture occurring. Strain energy could be released through stable circumferential microcracks emanating from near the edges of the indent craters, but without film spallation. 
Although bare titanium and Ti-6Al-4V alloy is not considered appropriate in articulating biomedical implants because of its poor wear characteristics, NSD coating of these materials may be a viable solution as long as coating adhesion is not a concern. The high hardness, low surface roughness, excellent adhesion and resiliency of these coatings should be considered when searching for alternative bearing surfaces in total joint replacements.

Diamond on steel substrates-CVD deposition of diamond onto substrates comprising primarily transition elements cobalt, iron or nickel is inherently difficult because of the propensity of these elements to act as a catalyst for graphite formation (Lettington and Steeds, 1994, Davis, 1993, Chen and Narayan, 1993) during initial stages of growth. An additional hurdle for diamond deposition on steel is the large mismatch in thermal coefficients of expansion $\left(1 \times 10^{-6} /{ }^{\circ} \mathrm{C}\right.$ for diamond and $17 \times 10^{-6} /{ }^{\circ} \mathrm{C}$ for stainless steel, at room temperature). This leads to residual stresses present in the diamond film upon cooling from the high deposition temperatures, leading to poor adhesion. Therefore, in addition to lower substrate temperature during deposition, manipulation of interfacial chemistry is often used to improve adhesion of diamond coatings on steel. The most common method to attempt to overcome the hindrances for diamond deposition on ferrous substrates is through the use of an intermediate layer or system of layers. Choice of the intermediate layer should be based on its ability to act as a diffusion barrier to carbon, and to allow strongly bonded metal carbides and/or other interfacial reaction layers, ideally without sharp discrete interfacial boundaries that may act as regions of stress concentration.

Many different intermediate layers or layer systems have been tried over the years, including the nitrides of chromium and titanium with mixed reports in achieving adhered diamond films for both systems (Fayer et al., 1995, Buijnsters et al., 2002, Negrea and Vermesan, 2000, Lorenz, 1995). Buijnsters et al. used arc-plated CrN interlayers for coating diamond onto austenitic AISI-type 316 stainless steel as well as high speed steel. The use of the $\mathrm{CrN}$ interlayer was found not to result in a continuous diamond film on the stainless steel, but good quality adherent coatings did form on the high speed steel for substrate temperature as low as $650^{\circ} \mathrm{C}$. Polini et al. (Polini et al., 2006) demonstrated that well-adherent diamond films can be grown on high speed steels using a TiC interlayer deposited by the physical vapour deposition (PVD) arc technique. Their results showed that diamond films deposited on rough $\mathrm{TiC}$ interlayers exhibited a wide distribution of stress values and that very large compressive stress (as much as $10 \mathrm{GPa}$ ) could be accommodated without delamination.

The use of a pack bording process to create a thick boride case on ferretic tool and austenitic stainless steel resulted in the formation of $\mathrm{FeB}$ and/or $\mathrm{Fe}_{2} \mathrm{~B}$ phases believed to have a strong influence on the adherence of the diamond films (Buijnsters et al., 2003). In particular, the presence of FeB on the surface of the borided steels resulted in very high thermal stresses and consequent delamination of the diamond films on both ferritic tool and austenitic stainless steels. The boron-rich FeB phase was deemed to be not desirable, as it is more brittle and the large difference in expansion coefficients between the $\mathrm{FeB}$ and $\mathrm{Fe}_{2} \mathrm{~B}$ phases leads to crack formation at the $\mathrm{FeB} / \mathrm{Fe}_{2} \mathrm{~B}$ interface. However, on the borided tool and stainless steels without the $\mathrm{FeB}$ phase (but with $\mathrm{Fe}_{2} \mathrm{~B}$ ), continuous and adherent diamond films with very low residual stress were obtained. Preliminary findings (Ballinger and Catledge, 2011) reveal improved adhesion of NSD coatings on 440C stainless steel ball 
bearings using a plasma surface modification process to create iron and chromium boride interfacial layers. The NSD coatings were found to adhere much better on the plasmaborided ball bearings when compared to bearings that instead had a titanium nitride interfacial layer. Overall, these results suggest that with appropriate interfacial structure and chemistry, well-adhered diamond coatings may be possible on a variety of steels, despite the large driving force for delamination from graphitic carbon and from thermal expansion mismatch.

\subsection{Wear measurements for ceramic-based orthopaedic implants}

Fully dense ceramics, alumina and zirconia, are used in total joint replacements specifically for the purpose of providing more wear resistant bearing surfaces. Because of their hardness, ceramics can be polished to a very smooth finish and remain relatively scratch resistant while in use as a bearing surface. The most significant disadvantage of ceramics is their brittle nature, making them susceptible to fracture. Improvements in metallurgy have sparked renewed interest of metal-on-metal bearings, and similarly, improvements in ceramic quality have led to increased interest in ceramic bearings. Over the long term, alumina-onpolyethylene bearings for hip replacement show reduced wear rates over those typically seen with metal-on-polyethylene bearings, with an associated decrease in osteolysis (Wright et al., 2009). However, the use of zirconia as a bearing surface against polyethylene has not proven as successful clinically as aluminaon-polyethylene bearings. In comparing alumina-, zirconia-, and metal-on-conventional polyethylene bearings in total hip patients, the highest wear rate occurs in the zirconia group. Zirconia, which is as wear resistant as alumina, tends to change its crystalline structure to a form that is less tough and more prone to wear. In general, alumina-on-alumina joints have shown very low wear rates clinically, although the results are design dependent. Recent reports also show excellent wear resistance in young patients, with no measurable wear and no evidence of osteolysis even beyond a decade of follow-up (Wright et al., 2009). Furthermore, very few implant fractures have been observed, even in this high demand patient population, providing support for the improved mechanical properties of alumina. Oxidized zirconium is used for femoral heads in hip replacement and the femoral component in knee replacement, and initial results look promising. However, longer term studies will be needed to prove that the improved bearing properties of oxidized zirconium lead to longer lasting implants.

\subsubsection{Wear of diamond-like carbon coatings for orthopaedic implants}

A review of ceramic coatings for orthopaedic implants shows that the significant research effort devoted to develop TiN and DLC coatings for orthopaedic bearings by many research groups worldwide has not led to widespread clinical applications (Piconi et al., 2004). The laboratory tests on DLC coatings often show conflicting and controversial results on the improvements in wear in comparison to CoCr alloy. A comparison of these results shows that care must be taken with regard to the source of DLC, methane being superior to acetylene, and above all to the smoothness of the substrate. When conditions are favourable, the tests indicate that DLC coatings have the potential to provide the lowest wear rates of ultrahigh molecular weight polyethylene (UHMWPE), perhaps half that against alumina, without the risks associated with fracture of ceramic components. However, better control of 
the high internal stresses in these coatings may be needed in order to avoid issues with coating spallation and detachment.

With regard to application involving orthopaedic materials, hard DLC coatings have been deposited on $\mathrm{CoCr}$ and magnesia-stabilized zirconia substrates, with enhanced scratch resistance on the latter substrate due to its better resistance to plastic deformation (Roy et al., 2009). DLC-coated titanium alloy femoral heads performed well in hip simulator tests (Affatato et al., 2000) but fared poorly in clinical use (Taeger et al., 2003). DLC-coated $\mathrm{CoCr}$ alloy femoral heads were undamaged in aggressive wear tests employing third-body bone cement particles (Santavirta et al., 1999), but hip simulator tests using bovine serum as a lubricant have not shown reduced polyethylene wear compared to non-coated $\mathrm{CoCr}$ heads (Saikko et al., 2001, Galvin et al., 2007). Wear tests aimed to evaluate DLC as a coating for tibial trays of knee prostheses (Jones et al., 2001) measured 3.5 increase in wear of UHMWPE pins sliding against DLC-coated vs. cast $\mathrm{CoCr}$ alloy plates, leading the authors to remark on the unsuitability of DLC coating for the intended application. Also the results of biaxial hip simulator tests were controversial: similar wear of UHMWPE cups against $\mathrm{CoCr}$ DLC-coated and uncoated heads was reported (Saikko et al., 2001), both values higher than the wear of the same cups against alumina heads, whereas other authors (Affatato et al., 2000) measured wear rates of UHMWPE cups similar for alumina and DLC-coated heads, both higher than $\mathrm{CoCr}$ coupled to the same cups. In pin-on-disk tests against PMMA pins (Mishra and Davidson, 1992), DLC-coated Ti6Al4V disks performed worse than wrought CoCrMo alloy raising doubts about coating resistance to third-body wear. In comparison, several reports involving DLC are very encouraging. An original bearing couple DLC-onDLC was tested in a simplified hip simulator and in pin-on-disk wear tests with satisfactory results (Lappalainen et al., 1998). In a National Science Foundation (NSF)-funded study, Xu and Pruitt (Xu and Pruitt, 1999) examined DLC coatings on Ti-6Al-4V alloy against UHMWPE in pin-on-disk tests in water. The DLC was prepared by the plasma source method described above. The rate of PE wear was reduced by a factor of 3-4, compared with uncoated alloy. For amorphous diamond coatings deposited by pulsed plasma arc techniques, the wear rates determined in a commercial hip simulator for 15 million walking cycles (corresponding to about 15 years of clinical use) in serum lubrication were even $1,000,000$ times lower than the clinical values for conventional total hip replacements (THRs) (polyethylene-metal or metal-metal pairs) (Lappalainen et al., 2003). Clearly, the variability of reports for the effectiveness of DLC in orthopaedic wear couples must be treated with caution, and may be explained, at least in part, by differences in coating roughness and test procedure (Dearnaley and Arps, 2005).

\subsubsection{Wear of nanostructured diamond coatings for orthopaedic implants}

NSD coatings have been tested to a much lesser extent than DLC coatings. The NSD coatings could prove to be more resistant to scratching by third-body wear particles, such as bone cement, due to the high hardness of the coatings (56-72 GPa) (Papo et al., 2004). In one study (Hill et al., 2008), NSD coatings were deposited onto Ti6Al4V by microwave plasma-assisted chemical vapour deposition (MPCVD), with both hydrogen-rich, NSD-(H), and helium-rich, NSD-(He), feedgas mixtures. Pin-on-disk wear testing was performed in serum lubrication with an OrthoPOD ${ }^{\circledR}$ wear tester to evaluate the wear of polyethylene 
against the NSD coatings and CoCr. The average wear factor calculated for polyethyleneon-CoCr, $5.7 \pm 0.8 \times 10^{-7} \mathrm{~mm}^{3} / \mathrm{Nm}$, falls within the range determined from retrieval studies of total replacement hip joints, $9.0 \times 10^{-8}-7.2 \times 10^{-6} \mathrm{~mm}^{3} / \mathrm{Nm}$ (Atkinson et al., 1985). As shown in Fig. 5.7, no statistically significant difference in wear factor was found between polyethylene against NSD-(H), NSD-(He) and CoCr. However, polyethylene experienced lower wear against nine of the 12 NSD samples compared to CoCr, despite NSD exhibiting higher roughness and higher coefficient of friction against polyethylene. Scanning electron microscopy (SEM) images of the worn pins revealed multiple protuberances of polyethylene rising above the surface in polyethylene-on-CoCr, and a single, large, elevated protuberance in polyethylene-on-NSD. These protuberances were thought to be areas of high wear resistance. It was concluded that as a counterface to polyethylene, NSD coatings gave comparable wear with CoCr, with several NSD samples giving lower wear. Although pinon-disk wear testing is a valid screening tool for candidate materials, similar results may not be observed in vivo. Although the present wear results for the polyethylene-on-CoCr were consistent with those found in the literature, simulator studies are required to further evaluate the NSD coatings. To examine the resistance of NSD to this third-body damage, bone cement particles should be added to future wear tests of polyethylene-on-NSD. Investigation into the role of protein concentration and on the formation of the polyethylene surface features may provide further insight into the wear mechanisms.

\subsection{Mesenchymal stem cells derived from bone marrow and their interactions with nanostructured diamond surfaces}

Clinical success of diamond coated orthopaedic implants that required to be anchored in surrounding bone tissue requires biointegration resulting from the growth of bone-forming osteogenic cells onto the surface in vivo. Therefore, orthopaedic materials designed for bone implantation are tested in vitro on cell cultures and then in vivo on animals to evaluate their efficacy for cell growth and subsequent bone formation. The anchorage-dependent cells studied on these materials typically adhere with spreading across tens of micrometres (Stevens and George, 2005). Under in vitro conditions, usually, the materials or surfaces are allowed to interact with either established cell lines or primary cells derived from laboratory animals. Examples of animal cell lines often used for bone-implant screening as well as for bone-tissue engineering include osteoblast-like UMR-106 cells, mouse bone marrow MBA-15 cells and mouse progenitor MC3T3-E1 cells (having a fibroblast-like phenotype capable of differentiating into osteoblasts in appropriate culture environments (Kanazawa et al., 2007). Human bone-derived cell lines (derived from osteosarcoma) include osteoblastlike cells CPC-2, TE-85, MG-63, SaOS-2 and U-2OS. Although these cell lines generally retain the most important markers of osteogenic cell differentiation, such as the activity of alkaline phosphatase and production of osteocalcin (Zhao et al., 2007, Amaral et al., 2008, Rudnik et al., 2008, Kalbacova et al., 2009, Vandrovcova and Bakacova, 2011), as a result of tumour origin, they may sometimes lose their markers of differentiation compared to primary low-passaged cells (Tan and Saltzman, 2004).

Primary cells of animal and human origin used to interact with materials for bone implants or scaffolds for bone regeneration include differentiated osteoblasts, such as osteoblasts 
from neonatal rat calvaria (Webster et al., 2000a,b, de-Oliveiera and Nanci, 2004, deOliveira et al., 2007), human osteoblasts (hOB) obtained from surgical bone specimens (Anselme and Bigerelle, 2005) and also stem cells, such as mesenchymal stem cells derived from the bone marrow (Clem et al., 2008, Kilpadi et al., 2004, Jose et al., 2010) or embryonic stem cells (Bedi et al., 2009). Adhesion, growth and differentiation of osteoblasts on the surface of materials developed for bone implants were reviewed recently by Vandrovcova and Bacakova et al (Vandrovcova and Bakacova, 2011). Multipotent mesenchymal stem cells (MSC), which can rapidly proliferate in response to injury (Caplan, 2005) and differentiate into a variety of functional cells including bone forming osteoblasts, have attracted much attention in orthopaedic research (Deans and Moseley, 2000). As MSCs differentiate into a committed cell type, they lose their ability for rapid proliferation (Bruder et al., 1994). For this reason, it is the MSCs, rather than osteoblasts, that are primarily recruited for early stage bone healing (Okumura et al., 1997). The process of bone deposition on the surface of a biomaterial is thought to be dependent on cell attachment and proliferation of MSCs on the material surface, followed by osteoblastic differentiation, and finally, production of a mineralized matrix. Attachment of MSCs occurs primarily via integrin receptors, which recognize specific sequences on extracellular matrix (ECM) proteins. Integrins are composed of an $\alpha$-subunit and a $\beta$-subunit, which together recognize specific peptide-domains on collagen, laminin, fibronectin, vitronectin, fibrinogen, osteopontin, sialoprotein and others which mediate the cell adhesion on artificial implant materials. As blood contains large amounts of fibronectin, vitronectin and fibrinogen, spontaneous adsorption of these proteins onto the surface of materials with a geometrical conformation favouring good contact between their specific bioactive sites (e.g. RGDs) and cell-integrins can increase biomaterial capacity for cell attachment. As integrins attach to ECM proteins, they activate intracellular cascade events that regulate cell spreading, proliferation, migration and differentiation (Giancotti, 1999). It has been recently reported that MSC attachment to adhesive proteins, such as fibronectin, occurs by different mechanisms than those in attachment of cell lines (Kilpadi et al., 2004, Vohra et al., 2008). For example, MG-63 and Saos- 2 cell attachment to fibronectin is mediated by both $a 5$-and $a \mathrm{v}$-containing integrin heterodimers, whereas only $a \mathrm{v}$-containing integrins are used by MSCs in fibronectin adhesion. Additionally, MSCs have higher levels of $a 2$-integrin subunits than either MG-63 or Saos-2 cells (Vohra et al., 2008).

CVD diamond surfaces are biocompatible, according to Tang et al. (Tang et al., 1995), who were among the first to report the biocompatibility of CVD diamond, comparable with titanium and stainless steel. Since then, NSD surfaces or films produced by CVD technique have been repeatedly shown to be an excellent noncytotoxic material for cell adhesion and growth (Fig. 5.8) in biotechnological applications (Bacakova et al., 2008, Rezek et al., 2011). Many recent studies, using a variety of cell types such as osteoblasts (Amaral et al., 2008, Kalbacova et al., 2009, Yang et al., 2009a), fibroblasts (Amaral et al., 2009), epithelial cells (Lechleitner et al., 2008), endothelial cells (Grousova et al., 2008), bone marrow derived MSCs (Clem et al., 2008) and neural cells (Chen et al., 2009), have focused to understand and control the cell responses on NSD by varying the CVD process parameters to obtain nanocrystallinity, grain size and roughness and also post-surface treatments to obtain different surface chemistry, wettability, and surface functional groups 
and surface change and conductivity. General findings from these studies so far are that NSD surfaces enhance the growth of osteogenic cells including mesenchymal stem cells and that control of cell adhesion, proliferation and subsequent bone formation can be achieved by altering NSD surface properties as a result of the correlation between the surface properties and the adsorbed endogeneous proteins that regulate the cell behaviour (Clem et al., 2008, Kanazawa et al., 2007, Kloss et al., 2008b).

\subsubsection{Effect of nanotopology and nanoroughness}

It is well documented that cells respond differently to nanostructured compared with conventional classic material topographies in terms of cell adhesion, proliferation and function (Kalbacova et al., 2009, Webster et al., 2000a, Catledge et al., 2002, Grausova et al., 2011). Many features of nanofibre or nanophase or nanostructured materials with irregularities less than $100 \mathrm{~nm}$ mimic or simulate the nanoscaled architecture of native ECM, irregularities of biomacromolecules such as folding, branching etc., and size of ECM parts of cell adhesion receptors (Thomas et al., 2006). Regarding the major bone constituents, hydroxyapatite (the major mineral component) is between 2 and $5 \mathrm{~nm}$ in width and $50 \mathrm{~nm}$ in length; Type I collagen (the major protein component of bone tissue) is 300 $\mathrm{nm}$ in length, $0.5 \mathrm{~nm}$ in width and has a periodic bandwidth of $67 \mathrm{~nm}$ (Thomas et al., 2006, Kaplan et al., 1994). The osteogenic cells interact with surfaces with a large degree of nanometric-scale morphological features. Surface roughening treatments have been performed on the anchoring region of an implant in order to generate interlocking with bone for stabilization. Webster's research group has published several reports demonstrating increased adhesion of osteoblasts on nanophase ceramics as well as polymer-ceramics nanocomposites (Webster and Smith, 2005, Kay et al., 2002, Webster and Ejiofor, 2004, Palin et al., 2005, Balasundaram et al., 2006). Studies on primary rat calvarial osteoblast cultured on nanophase titania (grain size 20-56 nm), alumina (grain sizes 20-67nm) and conventional much rougher titania and alumina (grain sizes $2120 \mathrm{~nm}$ and $177 \mathrm{~nm}$ ) demonstrated increased attachment of osteoblast on nanophase ceramics (Webster et al., 1990). Human osteoblast like MG63 cells cultured on titania $(\mathrm{Ra}=40 \mathrm{~nm})$ also induced larger cell-spreading and higher cell numbers (viability) than surface with higher roughness $(\mathrm{Ra}=100-170 \mathrm{~nm})($ Vandrovcova et al., 2010). Enhanced cell performance on nanophase materials was attributed to the higher number of surface atoms, surface defects and grain boundaries (Webster, 2004), which in turn have been shown to influence initial protein adsorption in terms of concentration, conformation and bioactivity, the factors that trigger and control cell adhesion and proliferation (Webster et al., 2000a,b).

Regarding the NSD coating, which is a nanocrystalline material, composed of agglomerated nanocrystals embedded in amorphous carbon matrix having topographical features (roughness and grain size) in nanoscale, the same nanofeatures can be extrapolated from nanophase ceramics. The quantitative increase in the total length of grain boundaries and total number of pores between surface particles of NSD provide very high surface area-tovolume ratio compared with micron-structured diamond surfaces. Therefore, cell culture on NSD grains exposes cells to an increased number of grain boundaries favouring a positive cell behaviour. Among nanocrystalline diamond surfaces created with identical grain size $(200 \mathrm{~nm})$, but with nano-roughness $(\mathrm{RMS}=20 \mathrm{~nm})$, nano/micro-roughness $(\mathrm{RMS}=270 \mathrm{~nm})$ 
and micro-roughness ( $\mathrm{RMS}=500 \mathrm{~nm}$ ), the nano-rough surface of $20 \mathrm{~nm}$ provided the best results for the initial adhesion of SaOS-2 cells, for metabolic activity, for osteogenic differentiation and biomineralization (Kalbacova et al., 2009). However, in an early study, Bacakova et al. (2007) reported that the best osteoblast proliferation could be on diamond with combined micro-and nano-structured features compared to NCD and polystyrene (PS) plates. A search for the optimum roughness for a better bone fixation on diamond surface concluded that nanocrystalline diamond (ND) with grain sizes $<100 \mathrm{~nm}$ and roughness $<20$ $\mathrm{nm}$ promoted osteoblast functions, that could be due to its similarity to the topography of a real bone surface (Kalbacova et al., 2009), whereas microcrystalline diamond (MD) with larger grain sizes ( $200 \mathrm{~nm}$ to $2 \mu \mathrm{m}$ ) prohibited these osteoblast functions (Yang et al., 2009b).

\subsubsection{Effect of terminal functional groups and surface wettability}

CVD deposited NSD is usually hydrogen terminated, which makes the surface hydrophobic with contact angles of $85-95^{\circ}$ range (Clem et al., 2008, Lechleitner et al., 2008, Yang et al., 2009b). Inducing oxygen terminal-functionalities on as-deposited NSD could render the surface highly hydrophilic with contact angle as low as $2^{\circ}$ (Clem et al., 2008). Oxygen plasma treatment was expected to enhance cell adhesion on nanodiamond films and several studies have confirmed this rationale (Kalbacova et al., 2009, Lechleitner et al., 2008, Kloss et al., 2008b). However, depending on the phenotype characteristics of cells used for the NSD interaction studies, mixed reports are found in literature. In a study, Lechleitner $e t$ al. (Lechleitner et al., 2008) reported that hydrogen-terminated NCD (hydrophobic) inhibited renal epithelial cell (HK-2 cell line) attachment but oxygen-terminated NCD (hydrophilic) improved HK-2 cell attachment and proliferation compared to borosilicate glass. According to the authors, this selective inhibition could be due to the lack of functional polar groups or interaction sites which prevent adherent cells from setting on the surface whether nanostructured or not. Hydrophilic O-terminated NCD on the other hand, appears to offer a multitude of interaction sites for polar and ionic components of the cell culture medium and subsequently favour the attachment of cells. Immobilization of BMP-2 on O-terminated nanocrystalline diamond followed by in vitro studies using primary human mesenchymal stromal cells and subsequent bone formation in vivo by implanting into sheep calvaria confirmed this fact (Kloss et al., 2008b).

Our studies (Clem et al., 2008) performed on the mesenchymal cell cultures on the surface of USND (RMS $=5 \mathrm{~nm}$ ) with terminal functional group such as H-terminal hydrophobic USND, F-terminated hydrophobic USND and O-terminated hydrophilic USND, revealed that MSC adhesion and proliferation favoured on H-terminated NSD but not on Fterminated or O-terminated NSD (Fig. 5.9). At shorter time (1 hour), numerous cells had adhered to the H-terminated samples and the cells had adopted a well-spread morphology, with pseudopodia extending randomly along the biomaterial surface (Fig. 5.10). In contrast, no cells attached to the F-terminated samples and a limited number of very rounded cells were observed on O-terminated NCD (Clem et al., 2008). At longer culture times, both Oterminated or F-terminated USND surfaces have been found to fully inhibit cell adhesion, whereas the H-terminated USND surfaces consistently supported adhesion and spreading of 
MSCs up to 14 days wherein a confluent layer had covered the surface, indicating that the MSCs were proliferating (Fig. 5.11).

The mechanism underlying the high degree of MSC adhesion to H-terminated, but not F- or O-terminated USND is not clear yet. It is known that cell adhesion is optimum on moderately hydrophilic surfaces. Highly hydrophilic substrates bind the cell adhesion mediating proteins with relatively weak forces (Bacakova et al., 2008), which can lead to the detachment of these proteins at a longer culture time. Another possibility may relate to the intrinsic surface conductive properties of $\mathrm{H}$-terminated surfaces. The opposite cell material behaviour of two H-terminated nanodiamond surfaces with more less similar contact angles $\left(86^{\circ}\right.$ and $\left.90^{\circ}\right)$ indicates that surface wettability alone is inadequate to explain the cell responses on NSD and that the role of other surface properties (such as surface atoms ratio, grain size etc) on the regulation of cells needs to be considered. Yang et al. (Yang et al., 2009a) have also compared the osteoblast cell functions on H-terminated nanocrystalline diamond (NCD) with grain sizes between 30 and $100 \mathrm{~nm}$ and submicron grain size 100 and $600 \mathrm{~nm}$ (SMCD) having similar wettability (92-98 contact angles). Osteoblastic short-term functions (such as adhesion and proliferation) and long-term functions (ALP activity, collagen synthesis and extra cellular calcium deposition) were found to be enhanced significantly on relatively smooth NCD (RMS roughness $=\sim 20 \mathrm{~nm}$ ) than on SMCD with rough diamond surface $(\mathrm{RMS}=60 \mathrm{~nm}$ ). SEM imaging (Fig. 5.12) of the osteoblast filopodia protrusions on NCD and SMCD revealed that filopodia on NCD spread randomly, indicating a greater number of focal contact sites on surface via optimal protein interactions, whereas many filopodia converged on minimal site on SMCD, indicating only a few protein binding sites on the surface (Yang et al., 2009a). It is asserted that two adhesive sites with proper receptors on adjacent grains with a separation greater than $73 \mathrm{~nm}$ might limit osteoblast spreading and subsequent proliferation, as reported by Arnold et al. (Arnold et al., 2004). However, it is noteworthy that hydrophobic H-terminated NCD exhibited favourable longterm osteoblast functions comparable or better than those of hydrophilic Bioglass (contact angle $\sim 38^{\circ}$ ) and silicon surface (contact angle $\sim 32^{\circ}$ ) as observed in Fig. 5.13 (Yang et al., 2009a). In a recent study Pareta et al. (Pareta et al., 2010) showed that among the $\mathrm{H}_{2}, \mathrm{O}_{2}$ and $\mathrm{NH}_{3}{ }^{-}$plasma treated $\mathrm{NCD}$, enhanced osteoblast adhesion was observed on $\mathrm{NH}_{3}{ }^{-}$plasma treated NCD. Further systematic studies might be useful to elucidate the extent to which both surface chemistry and wettability play a role in cell adhesion and growth in the case of mesenchymal stem cells.

\subsubsection{Effect of electric conductivity of surface}

Electric properties (electric charge, potential and conductivity) have been reported to favour positively on the cell performance even without additional electrical stimulation in the case neural cells, cardiac myoblasts and bone cells also. H-terminated CVD diamond surface posses p-type surface conductivity and show negative electron affinity (Pakes et al., 2007). The p-type electrical conductivity of NCD films can be further improved by boron doping (Gajewski et al., 2009). Only a couple of studies reported the influence of boron doped NCD films on the adhesion, growth, differentiation and functions of osteoblasts (Grausova et al., 2011, Kopecek et al., 2008). Human osteoblast-like MG 63 cells cultured on NCD with varying concentrations of boron $(133,1000$ and $6700 \mathrm{ppm})$ indicated that the highest 
number of cells were obtained on NCD with low and medium boron concentrations (Grausova et al., 2011). However, NCD films with the highest boron concentration (6700 $\mathrm{ppm}$ ) indicated signs of increased cell matrix adhesion (manifested by the highest concentration of focal adhesion protein vinculin and increased adsorption of collagen I) and also osteogenic differentiation (suggested by a higher concentration of osteocalcin and ALP). The relatively low proliferation activity of cells on the samples of highest boron concentration was attributed, in part, to the higher amount of $\mathrm{sp}^{2}$ bonded carbon (graphite or amorphous carbon) and to the relatively higher hydrophilicity of the surface (water contact angle $\left.=13^{\circ}\right)($ Grausova et al., 2011). Although not well understood, these studies support the fact that p-type electric conductivity influences the cell attachment, growth and differentiation on the NSD surface.

\subsubsection{Effect of orthopaedic substrate chemistry}

A comparative study (Clem et al., 2008) of MSC attachment and growth to H-terminated USND coated surface and known orthopaedic implant surfaces such as CoCrMo and Ti-6Al-4V revealed that USND supported greater cell adhesion than CoCrMo, although less than Ti-6Al-4V (Fig. 5.14). Subsequent quantification of cell proliferation by MTT assay at 3-7 days indicated that MSCs exhibited a similar degree of proliferation on USND and Ti-6Al-4V (Fig. 5.15). A recent study by Pareta et al. (Pareta et al., 2010) revealed similar levels of osteoblast adhesion on H-terminated NCD-coated titanium and uncoated titanium with an osteoblast adhesion efficiency between $30 \%$ and $40 \%$ after 4 hours of culture. In contrast, reduced cell number on CoCrMo may reflect a slower rate of proliferation, reduced cell survival on CoCrMo or both (Clem et al., 2008). Attachment and proliferation of MSCs to the surface of the biomaterial are critical steps in the osseointegration of an implant. Cellular response to biomaterials depends initially on the interaction of adhesion receptors with proteins adsorbed to the surface. Adsorbed proteins can be detected on biomaterials within a second of exposure to the blood, and a monolayer of adsorbed proteins forms in seconds to minutes (Raffaini and Ganazzoli, 2007). Fibronectin, vitronectin and fibrinogen are pro-adhesive proteins that are recognized by various cellular integrins and platelet receptors, and play an important role in the initial recruitment of cells to the implant surface. Surface properties (surface energy, charge, chemistry, topography and wettability) influence greatly the protein adsorption and subsequent confirmation. Ideally, the proteins should adsorb in a confirmation that allows for the pro-adhesive motifs, such as RGD, to be accessible by MSC or osteoblastic integrins.

Ultimately, firm fixation of an orthopaedic implant depends on deposition of mineralized matrix directly on the surface of the implant by osteoblasts. For osseointegration of an implant, the implant surface should not only support the attachment and proliferation of MSCs, but also favour the differentiation of stem cells along an osteoblastic lineage (bone forming cells). Our studies (Clem et al., 2008) by quantification of calcium content for the MSC cultured on H-terminated NCD surface, cobalt chrome and titanium alloy (under osteogenic condition, $\mathrm{OS}+$ ) showed that similar amounts of mineralized matrix were deposited by the cells onto USND and cobalt chrome, whereas a slight increase in mineral deposition was observed for titanium alloy (Fig. 5.16). Processes of osteoblastic 
differentiation and matrix mineralization occurring readily on USND coatings is an indicator for osseointegration necessary for anchoring regions of bone implants.

\subsection{Macrophage cell interactions to diamond wear debris}

As mentioned previously, wearing of joint-implants and the generation of wear-debris particles can lead to mechanical instability, decreased joint mobility, increased pain, deleterious biological responses, osteolysis and ultimately component loosening and implant failure (Mercuri, 2000b, Maloney and Smith, 1995, Bauer, 2002, Wang et al., 2004, Archibeck et al., 2001, Purdue et al., 2007, Aspenberg, 1996). Macrophages are the primary scavengers of wear debris particles and their response appears to depend on the nature, size and concentration of particles accumulated. Large debris pieces are normally sequestered by fibrous tissue, whereas small debris is phagocytosed by macrophages and multinucleated giant cells. Phagocytic cells engulf wear debris and become activated, releasing proinflammatory cytokines, degradative enzymes and other factors that stimulate osteoclasts (Ingham and Fisher, 2005, Glant et al., 1993, Merkel et al., 1999) at the bone implant interface and the bone resorption around the implant.

Regarding NSD-coated implants; the brittleness/delamination of a thin diamond coating may lead to the formation wear debris of nanodiamonds from diamond-on-diamond and diamond-on-polyethylene couples. In a hip simulator study (Lappalainen et al., 2003), diamond-diamond couples have shown a huge reduction in wear debris volume $\left(<10^{-4}\right.$ $\mathrm{mm}^{3} /$ year), compared to first-generation CoCrMo-CoCrMo couples (1-5 $\mathrm{mm}^{3} /$ year) and to couples using polyethylene (50-100 $\mathrm{mm}^{3} /$ year). The reduced wear volume and particle size expected for diamond articulation is a major advantage over conventional orthopaedic bearings. Similarly the average particle size of debris produced from a diamond-on-diamond and diamond couple is expected to be considerably smaller than polyethylene debris due to its superior hardness, smoothness and wear-resistant properties. However, a very low wear volume itself is not the only key factor governing the long-term clinical outcome of a total joint replacement. The number, size or morphology and biological response to any wear particles released are also important. In addition, there exists considerable discussion over the possible distribution of these smaller nanoparticles in the body, and their biological effects on cells and tissues. A few studies have reported the cytocompatibility of detonation nanodiamond particles $(2-10 \mathrm{~nm})$ from a standpoint of cell viability using MTT assay and ATP production or reactive oxygen species (ROS) measurement with different cell types, including macrophages (Schrand et al., 2007, Huang et al., 2008). A variety of cells of other phenotypes, such as neuroblastoma cells, keratinocytes, macrophages and pheochromocytoma P12 cells, in cultures on NCD films or exposed to diamond nanoparticle suspensions (concentration of $5-100 \mathrm{mg} / \mathrm{mL}$ of the culture media), also retained their typical morphology, metabolic activity and viability (Schrand et al., 2007). Moreover, diamond nanoparticles were found to generate no significant amount of ROS (Schrand et al., 2007). In cultures of HeLa cells, micro sized diamond crystals (diameter approximately $1 \mu \mathrm{g} / \mathrm{mL}$, concentration $\geq 1 \mu \mathrm{m} / \mathrm{mL}$ ) caused considerable stress to the cells and attenuated their growth and viability, whereas nanodiamond crystals (diameter $\sim 2 \mathrm{~nm}$ ) showed no harmful effects in comparable concentrations (Fucikova et al., 2009). 
Activated macrophages generally release inflammatory cytokines and chemokines including bone-resorbing factors such as tumour necrosis factor $a$ (TNF $a$ ), interleukin (IL-6 and IL1), inducible nitric oxide synthetase (iNOs) etc., in response to increasing concentration of the wear debris (for a recent review, see Goodman and Ma, 2010). Huang et al. have reported no significant variation in the $m$ RNA levels for TNF $a$, IL- 6 and iNOS genes due to the exposure of detonation nanodiamond particles $(2-8 \mathrm{~nm})$ at a relatively low concentration of $30 \mu \mathrm{g} / \mathrm{mL}$ (Huang et al., 2008). In an objective to evaluate systematically the effect of size $(6-500 \mathrm{~nm})$ of synthetic nanodiamond particles as potential wear debris from diamond on diamond couples on cell toxicity, apoptosis and pro-inflammatory cytokine gene expression, we have recently cultured RAW 264.7 macrophage cells in a medium containing freefloating diamond particles (10-200 $\mu \mathrm{g} / \mathrm{mL}$ ) (Thomas et al., 2011). Figure 5.17 illustrates that cells both with and without the addition of ND solutions grew healthily, with no noticeable cell morphology difference. However, more elongated cells can be seen in PBS and in wells of low concentration particles $(20 \mu \mathrm{g} / \mathrm{mL})$ than wells of $70 \mu \mathrm{g} / \mathrm{mL}$ where they displayed a rounded morphology whether they had consumed particles or not. A reduction of relative mRNA levels was found for genes such as TNF- $\alpha$, IL-1 $\beta, \mathrm{Cxcl} 2, \mathrm{Ccl} 2$, VEGF and PDGF with the introduction of nanodiamonds $(50 \mu \mathrm{g} / \mathrm{mL})$ in culture medium (Thomas et al., 2011). But, apoptosis and necrosis (downstream events in response to cytotoxic stimuli) showed reduction in cell viability with a pronounced effect with smaller particles (6 and 60 $\mathrm{nm}$ ). This data were in agreement with the results obtained in BrdU assay by measuring the cells that are actively replicating their DNA (Thomas et al., 2011). This could be due to the increased number of particles with the size reduction at a constant concentration $(50 \mu \mathrm{g} / \mathrm{mL})$ and huge surface area of nanoparticles when size is reduced to $100 \mathrm{~nm}$ and below. A comparable in vitro study using stainless steel particles with the RAW 264.7 cell line reported upregulation of both TNF- $\alpha$ and IL- $1 \beta$ with a significant number of late apoptotic cells (Bailey et al., 2005).

The translational potential of the NSD-coated implants is in a large way determined by their biocompatibility and bio-performance (wear resistance of articulating surface and osteointegration of the rest). Failure or loosening of joint replacement components is often multifactorial (Revel, 2008). Among them, an important factor is wear debris and its response to macrophage mediated osteolysis, which can potentially occur in any implant system regardless of implant design or fixation mode. For this reason, the reduction of wear debris should be a primary goal of orthopaedic research. Although NSD coating can improve the smoothness and wear characteristics of metallic component of total hip replacements and increase their longevity, in vivo response of macrophage cells to the possible nanodiamond wear debris and the fate of phagocytosed nanodiamond (nanotoxicology) are not well understood and future translational research must be focused on these aspects.

\subsection{In vivo evaluation of nanostructured diamond surfaces}

Although the biocompatibility of DLC coatings has been well established through numerous studies (for a comprehensive review, see Dearnaley and Arps, 2005), a thorough in vivo evaluation of NSD coatings is lacking. Work by Kloss et al. (Kloss et al., 2008a) demonstrated that coating of endosseous implants with nanocrystalline diamond allows 
stable functionalization by means of physisorption with BMP-2. Strong physisorption was shown to be directly related to the unique properties of NCD, and BMP-2 in its active form interacted strongly when NCD was oxygen-terminated. Implant surfaces refined in such a manner yielded enhanced osseointegration in vivo, when inserted into sheep calvaria.

In another study, initial in vivo biocompatibility profiles showed evidence that bone integration with NSD may be comparable with Ti-6Al-4V, observed from staining of bone on the diamond surface. In this study (Lemons et al., 2003), the distal femoral and proximal tibial bone regions of four New Zealand white rabbits were aseptically implanted with $8 \mathrm{~mm}$ diameter by $2 \mathrm{~mm}$ thick discs (one side alloy, one side NSD-coated). Specimens were followed clinically and radiographically and examined macroscopically during euthanization at times to 8 weeks. Non-decalcified transversely oriented twin sections (five per disc) were prepared with an Exakt system; specimens were stained and examined by optical microscopy. All specimens showed trabecular and compact bone directly associated with the alloy $\left(\mathrm{TiO}_{2}\right)$ and diamond surfaces (biointegration), with no foreign body reactions and no abnormal characteristics within the marrow-bone spaces. It was concluded that the NSD coatings were similar macro- and microscopically to titanium alloy with respect to general and histological biocompatibility. The results, shown in Fig. 5.18, were consistent throughout the retrieved samples, indicating that NSD appears to be biocompatible and can perform well in applications where bone integration is needed.

\subsection{Future trends}

From a clinical perspective, the superior wear characteristics of NSD on metal prostheses may allow for a hard-on-hard approach of implant design providing a less invasive surgical procedure. In the current market the industry standard for orthopaedic and dental total joint replacement involves articulation of UHMWPE against a cobalt-chromium alloy. The UHMWPE component requires considerable thickness to stand up to the articular loads. In the case of the temporomandibular joint, for example, a hard-on-hard device (metal-onmetal device with NSD coatings on articular surfaces) engineered to be of sufficient rigidity to allow for a thin design of the fossa and condyle would allow for significant advantages: 1) allow for more minimally invasive surgery through a single incision; 2) allow for a more nature articulating position; 3 ) maintain normal structures such as the condyle and muscle attachments, maintaining normal muscle function; 4) the smaller design of the prosthesis with smaller surface area could result in a lower risk of infection; and 5) salvage procedures, if necessary, would be simpler to perform due to more native tissue being left in place.

Localized and 'on-demand' or prolonged drug delivery is also a priority for clinical research in implant devices. Electrochemical anodization of titanium has been used to create a layer of ordered titania nanotubes (inner diameters less than $100 \mathrm{~nm}$ ), which mimic the size and pattern of components of natural bone. Anodized titanium possessing nanotubular structures may be ideal drug storage matrices to locally deliver a wide range of drugs after implantation. Possible candidates for drugs to be delivered from nanotubular anodized titanium include those to fight infection, decrease inflammation and promote bone cell functions. The on-demand release of drugs could be triggered by local sonication near the implant site. 
Infusion of orthopaedic and dental materials with therapeutics, including antioxidants and antimicrobials is gaining more widespread acceptance in the marketplace. For example, the polyethylene used in orthopaedic devices has recently undergone new technology by infusion of vitamin $\mathrm{E}$, a naturally occurring antioxidant that can stabilize the free radicals that would otherwise lead to polyethylene oxidation and accelerated wear. Carbon-based nanomaterials also have potential as drug-carriers or free-radical scavengers. Fullerenes, for example, are believed to be extremely efficient antioxidants and are being investigated for biological applications. Fullerene- $\mathrm{C}_{60}$ is a non-toxic antioxidant $100-1000$ times more active than vitamin $\mathrm{E}$. Although $\mathrm{C}_{60}$ itself is not at all water soluble, many highly water soluble fullerene derivatives have now been prepared. Ultimately, it seems, nanoscale science and engineering for medical device development is relying more and more on the integration of structure, mechanical and biochemical functionality in its design. In this way, we hope to provide implant devices that are inherently less intrusive, longer lasting and more effective in fighting disease and infection.

\section{Acknowledgments}

The authors acknowledge support by Award Number R01AR056665 from the National Institute of Arthritis and Musculoskeletal and Skin Diseases. The content is solely the responsibility of the authors and does not necessarily represent the official views of the National Institute of Arthritis and Musculoskeletal and Skin Diseases or the National Institutes of Health.

\section{References}

Affatato S, Frigo M, Toni A. An in vitro investigation of diamond-like carbon as a femoral head coating. J Biomed Mater Res. 2000; 53:221-6. [PubMed: 10813761]

Ager JW III, Drory MD. Quantitative measurement of residual biaxial stress by Raman spectroscopy in diamond grown on a Ti alloy by chemical vapor deposition. Physical Review B. 1993; 48:26012607.

Amaral M, Fdias AG, Gomes PS, et al. Nanocrystalline diamond: In vitro biocompatibility assessment by MG 63 and human bone marrow cells cultures. J Biomed Mater Res A. 2008; 87:91-99. [PubMed: 18085649]

Amaral M, Gomes PS, Lopes MA, et al. Cytotoxicity evaluation of nanocrystalline diamond coatings by fibroblast cell cultures. Acta Biomater. 2009; 5:775-763.

Amstutz HC, Beaule PE, Dorey FJ, et al. Metal-on-metal hybrid surface arthroplasty: two to six-year follow-up study. J Bone Joint Surg Am. 2004; 86-A:28-39. [PubMed: 14711942]

Amstutz HC, Campbell P, Kossovsky N, Clarke IC. Mechanism and clinical significance of wear debris-induced osteolysis. Clin Orthop Relat Res. 1992:7-18. [PubMed: 1537177]

Amstutz HC, Grigoris P. Metal on metal bearings in hip arthroplasty. Clin Orthop Relat Res. 1996:S11-34. [PubMed: 8769320]

Anselme K, Bigerelle M. Topography effects of pure titanium substrates on human osteoblast longterm adhesion. Acta Biomater. 2005; 1:211-222. [PubMed: 16701798]

Archibeck MJ, Jacobs JJ, Roebuck KA, Glant TT. The basic science of periprosthetic osteolysis. Instr Course Lect. 2001; 50:185-195. [PubMed: 11372314]

Arnold M, Calvacanti-Adam EA, Glass R, et al. Activation of integrin function by nanopatterned adhesive interface. Chem Phys Chem. 2004; 5:383-8. [PubMed: 15067875]

Askari SJ, Chen GC, Lu FX. Growth of polycrystalline and nanocrystalline diamond films on pure titanium by microwave plasma assisted CVD process. Materials Research Bulletin. 2008; 43:1086-1092.

Aspenberg P. Benign response to particles of diamond and SiC: bone chamber studies of new joint replacement coating materials in rabbits. Biomaterials. 1996; 17:807. [PubMed: 8730965] 
ASTM_F732-00. Standard test method for wear testing of polymeric materials used in total joint prostheses. Philadelphia, PA: 2003.

Atkinson JR, Dowson D, Isaac JH, Wroblewski BM. Laboratory wear tests and clinical observations of the penetration of femoral heads into acetabular cups in total replacement hip joints: III: The measurement of internal volume changes in explanted Charnley sockets after 2-16 years in vivo and the determination of wear factors. Wear. 1985; 104:225-244.

Azevedo AF, Corat EJ, Ferreira NG, Trava-Airoldi VJ. Wettability and corrosion tests of diamond films grown on Ti6Al4V alloy. Surface and Coatings Technology. 2005; 194:271-275.

Bacakova I, Grausova L, Vacik J, et al. Improved adhesion and growth of human osteoblast-like MG63 cells on biomaterials modified with carbon nanoparticles. Diamond and Related materials. 2007; 16:2133-40.

Bacakova, L.; Grausova, L.; Vandrovcova, M., et al. Carbon nanoparticles as substrates for cell adhesion and growth.. In: Lombardi, SL., editor. Nanoparticles: New Research. Nova Science Publishers Inc, Hauppauge; New York: 2008.

Baek S, Mihec D, Metson J. Interfacial Properties Between CVD Diamond and Titanium. International Journal of Modern Physics B. 2003; 17:1127-1133.

Bailey LO, Lippiatt S, Biancanello FS, et al. The quantification of cellular viability and inflammatory response to stainless steel alloys. Biomaterials. 2005; 26:5296-5302. [PubMed: 15814127]

Bal Bs AT, Garino JP, Toni A, Hendricks KJ. Ceramic-on-ceramic versus ceramic-on-polyethylene bearings in total hip arthroplasty: Results of a multicenter prospective randomized study and update of modern ceramic total hip trials in the United States. Hip International. 2005; 15:129135.

Balasundaram G, Sato M, Webster TJ. Using hydroxyapatite nanoparticles and decreased crystallinity to promote osteoblast adhesion similar to functionalizing with RGD. Biomaterials. 2006; 27:27982805. [PubMed: 16430957]

Ballinger, J.; Catledge, SA. Adhered nanostructured diamond coatings on plasma borided stainless steel. 2011. unpublished results

Bauer TW. Particles and periimplant bone resorption. Clin Orthop Relat Res. 2002; 405:138-143. [PubMed: 12461365]

Beaule PE, Amstutz HC, Le Duff M, Dorey F. Surface arthroplasty for osteonecrosis of the hip: hemiresurfacing versus metal-on-metal hybrid resurfacing. J Arthroplasty. 2004; 19:54-8. [PubMed: 15578554]

Bedi RS, Beving DE, Zanello LP, Yan Y. Biocompatibility of corrosion-resistant zeolite coatings for titanium alloy biomedical implants. Acta Biomater. 2009; 5:3265-3271. [PubMed: 19433139]

Black, J. Biological Performance of Materials: fundamentals of bio-compatibility. Marcel Dekker; New York: 1992.

Bohn R, Haubold R, Birringer R, H. G. Nanocrystalline intermetallic compounds-An approach to ductility. Scripta Metall. Mater. 1991; 25:811.

Booth L, Catledge SA, Nolen D, Thompson RG, Vohra YK. Synthesis and Characterization of Multilayered Diamond Coatings for Biomedical Implants. Materials (Basel). 2011; 4:857-867. [PubMed: 21603588]

Bruder SP, Fink DJ, Caplan AI. Mesenchymal stem cells in bone development, bone repair, and skeletal regeneration therapy. J Cell Biochem. 1994; 56:283-94. [PubMed: 7876320]

Buccioni E, Braca E, Kenny JM, Terranova ML. Processing-structure-adhesion relationship in CVD diamond films on titanium substrates. Diamond and Related Materials. 1999; 8:17-24.

Buijnsters JG, Shankar P, Fleischer W, et al. CVD diamond deposition on steel using arc-plated chromium nitride interlayers. Diamond and Related Materials. 2002; 11:536-544.

Buijnsters JG, Shankar P, Gopalakrishnan P, et al. Diffusion-modified boride interlayers for chemical vapour deposition of low-residual-stress diamond films on steel substrates. Thin Solid Films. 2003; 426:85-93.

Caplan AI. Review: Mesenchymal Stem Cells: Cell-Based Reconstructive Therapy in Orthopedics. Tissue Engineering. 2005; 11:1198-211. [PubMed: 16144456]

Catledge S. High density plasma processing of nanostructured diamond films on metals. J. Appl. Phys. 1998; 84:6469. 
Catledge S. Effect of nitrogen addition on the microstructure and mechanical properties of diamond films grown using high-methane concentrations. J. Appl. Phys. 1999; 86:698.

Catledge S, Vohra Y. Effect of nitrogen addition on the microstructure and mechanical properties of diamond films grown using high-methane concentrations. Journal of Applied Physics. 1999; 86:698-698.

Catledge SA, Fries MD, Vohra YK, et al. Nanostructured ceramics for biomedical implants. J Nanosci Nanotechnol. 2002; 2:293-312. [PubMed: 12908255]

Catledge SA, Vaid R, Diggins PT, et al. Improved adhesion of ultra-hard carbon films on cobaltchromium orthopaedic implant alloy. J Mater Sci Mater Med. 2011; 22:307-16. [PubMed: 21221739]

Catledge SA, Vohra YK, Mirkarimi PB. Low temperature growth of nanostructured diamond on quartz spheres. J. Phys. D: Appl. Phys. 2005; 38:1410-1414.

Catledge SAAYKV. High Density Plasma Processing of Diamond Films on Titanium: Residual Stress and Adhesion Measurements. J. Appl. Phys. 1995; 78:7053.

Catledge, SAF.; M.; Vohra, YK. Nanostructured Surface Modifications for Biomedical Implants.. In: Nalwa, HS., editor. Encyclopedia of Nanoscience and Nanotechnology. American Scientific Publishers; 2004.

Chen X, Narayan J. Effect of the chemical nature of transition-metal substrates on chemical-vapor deposition of diamond. Journal of Applied Physics. 1993; 74:4168-4173.

Chen YC, Lee DC, Hsiao CY, et al. The effect of ultra nanocrystalline diamond films on the proliferation and differentiation of neural stem cells. Biomaterials. 2009; 30:3428-3435. [PubMed: 19406465]

Chowdhury S, Borham J, Catledge SA, et al. Synthesis and Mechanical Wear Studies of Ultra Smooth Nanostructured Diamond (USND) Coatings Deposited by Microwave Plasma Chemical Vapor Deposition with $\mathrm{He} / \mathrm{H}(2) / \mathrm{CH}(4) / \mathrm{N}(2)$ Mixtures. Diamond Related Materials. 2008; 17:419-427. [PubMed: 19112519]

Chowdhury S, Hillman DA, Catledge SA, et al. Synthesis of ultrasmooth nanostructured diamond films by microwave plasma chemical vapor deposition using a $\mathrm{He} / \mathrm{H} 2 / \mathrm{CH} 4 / \mathrm{N} 2$ gas mixture. Journal of Material Research. 2006; 21:2675-2682.

Clem WC, Chowdhury S, Catledge SA, et al. Mesenchymal stem cell interaction with ultra-smooth nanostructured diamond for wear-resistant orthopaedic implants. Biomaterials. 2008; 29:34613468. [PubMed: 18490051]

Corvin R. Gas-phase thermodynamic models of nitrogen-induced nanocrystallinity in chemical vapordeposited diamond. Appl. Phys. Lett. 2002; 80:2550.

Cuckler JM. The rationale for metal-on-metal total hip arthroplasty. Clin Orthop Relat Res. 2005; 441:132-6. [PubMed: 16330995]

Davis, RF. Diamond Films and Coatings. Noyes Publications; New Jersey: 1993.

De-Oliveiera PT, Nanci A. Nanotexturing of titanium-based surfaces upregulates expression of bone sialoprotein and osteopontin by cultured osteogenic cells. Biomaterials. 2004; 25:403-413. [PubMed: 14585688]

De-Oliveira PT, Zalzal SF, Beloti MM, et al. Enhancement of in vitro osteogenesis on titanium by chemically produced nanotopography. J Biomed Mater Res A. 2007; 80:554-564. [PubMed: 17031821]

Deans RJ, Moseley AB. Mesenchymal stem cells: Biology and potential clinical uses. Experimental Hematology. 2000; 28:875-884. [PubMed: 10989188]

Dearnaley G, Arps JH. Biomedical applications of diamond-like carbon (DLC) coatings: A review. Surface and Coatings Technology. 2005; 200:2518-2524.

Dementjev, AP.; Petukhov, MN. The role of oxygen atoms in sp2-sp3 conversion on the growing surface of carbon film.. In: Gielisse, PJ.; Ivanov-Omskii, VI.; Popovici, G.; Prelas, M., editors. Diamond and Diamond-Like Film Applications. Technomic Publishing Company, Inc.; Lancaster, PA: 1998.

Drory MD, Hutchinson JW. Diamond Coating of Titanium Alloys. Science. 1994; 263:1753-1755. [PubMed: 17795384] 
Fayer, A.; Glozman, O.; Hoffman, A. Deposition of continuous and well adhering diamond films on steel. AIP; 1995.

Ferrari A, Robertson J. Raman Signature of Bonding and Disorder in Carbons. MRS Proceedings. 1999; 593:299.

Friedmann, TA.; Sullivan, JP.; Knapp, JA., et al. Thick stress-free amorphous-tetrahedral carbon films with hardness near that of diamond. AIP; 1997.

Fu Y, Du H, Sun CQ. Interfacial structure, residual stress and adhesion of diamond coatings deposited on titanium. Thin Solid Films. 2003; 424:107-114.

Fucikova A, Valenta J, Pelant I, Brezina V. Novel use of silicon nanocrystals and nanodiamonds in biology. Chem Pap. 2009; 63:704-708.

Galvin AL, Tipper IL, Jennings LM, et al. Wear and biological activity of highly crosslinked polyethylene in the hip under low serum protein concentrations. Proceedings of the Institution of Mechanical Engineers. Part H, Engineering in Medicine. 2007

Gajewski W, Achatz P, Williams OA, et al. Electronic and optical properties of boron-doped nanocrystalline diamond films. Phys Rev B. 2009; 79:045206.

Giancotti FG. Integrin Signaling. Science. 1999; 285:1028-33. [PubMed: 10446041]

Glant TT, Jacobs JJ, Molna RG, et al. Bone resorption activity of particulate-stimulated macrophages. J Bone Miner Res. 1993; 8:1071-1079. [PubMed: 8237476]

Glyn-Jones S, Gill HS, Mclardy-Smith P, Murray DW. Roentgen stereophotogrammetric analysis of the Birmingham hip resurfacing arthroplasty. A two-year study. J Bone Joint Surg Br. 2004; 86:172-6. [PubMed: 15046428]

Godbole VP, Narayan R, Xu Z, Narayan J, Sankar J. Diamond films and composites on cobaltchromium alloys. Materials Science and Engineering B. 1999; 58:251-257.

Goldring SR, Schiller AL, Roelke M, et al. The synovial-like membrane at the bone-cement interface in loose total hip replacements and its proposed role in bone lysis. J Bone Joint Surg Am. 1983; 65:575-84. [PubMed: 6304106]

Good V, Ries M, Barrack RL, et al. Reduced wear with oxidized zirconium femoral heads. Journal of Bone and Joint Surgery-American Volume. 2003; 85A:105-110.

Good V, Widding K, Hunter G, Heuer D. Oxidized zirconium: a potentially longer lasting hip implant. Materials and Design. 2005; 26:618-622.

Goodman SB, Ma T. Cellular chemotaxis induced by wear particles from joint replacements. Biomaterials. 2010; 31:5045-5050. [PubMed: 20398931]

Grausova L, Kromka A, Burdikova Z, et al. Enhanced growth and osteoblastic differentiation of human osteoblast-like cells on boron doped nanocrystalline diamond thin films. PLos ONE. 2011; 6:e20943. doi:10.1371/journal.pone.0020943. [PubMed: 21695172]

Grierson, DS.; Sumant, AV.; Konicek, AR., et al. Thermal stability and rehybridization of carbon bonding in tetrahedral amorphous carbon. AIP; 2010.

Grousova L, Kromka A, Bacakova L, et al. Bone and vascular endothelial cells in cultures on nanocrystalline diamond films. Diamond Relat Mater. 2008; 17:1405-1409.

Gutmanas EY, Gotman I. PIRAC Ti nitride coated Ti-6Al-4V head against UHMWPE acetabular cuphip wear simulator study. Journal of Materials Science-Materials in Medicine. 2004; 15:327-330. [PubMed: 15332594]

Hallab N, Merritt K, Jacobs JJ. Metal sensitivity in patients with orthopaedic implants. J Bone Joint Surg Am. 2001; 83-A:428-36. [PubMed: 11263649]

Hendry JA, Pilliar RM. The fretting corrosion resistance of PVD surface-modified orthopedic implant alloys. Journal of Biomedical Materials Research. 2001; 58:156-166. [PubMed: 11241334]

Hill MR, Catledge SA, Konovalov V, et al. Preliminary tribological evaluation of nanostructured diamond coatings against ultra-high molecular weight polyethylene. J Biomed Mater Res B Appl Biomater. 2008; 85:140-8. [PubMed: 17853416]

Huang H, Pierstorff E, Osawa E, Ho D. Protein-Mediated Assembly of Nanodiamond Hydrogels into a Biocompatible and Biofunctional Multilayer Nanofilm. ACS Nano. 2008; 2:203-12. [PubMed: 19206620] 
Ingham E, Fisher J. The role of macrophages in osteolysis of total joint replacement. Biomaterials. 2005; 26:1271-86. [PubMed: 15475057]

Innocenti M, Civinini R, Carulli C, et al. The 5-year Results of an Oxidized Zirconium Femoral Component for TKA. Clinical Orthopaedics and Related Research. 2010; 468:1258-1263. [PubMed: 19798541]

Jin S. Effect of nitrogen on the growth of diamond films. Appl. Phys. Lett. 1994; 65:403.

Jones VC, Barton DC, Auger DD, et al. Simulation of tibial counterface wear in mobile bearing knees with uncoated and ADLC coated surfaces. Biomed Mater Eng. 2001; 11:105-15. [PubMed: 11352110]

Jose MV, Thomas V, Xu Y, et al. Multifunctional aligned nanofibrous nanocomposite scaffolds of PLGA/Collagen/HA for bone tissue engineering Macromol. Biosci. 2010; 10:433-444.

Kalbacova M, Rezek B, Baresova V, et al. Nanoscale topography of nanocrystalline diamonds promotes differentiation of osteoblasts. Acta Biomater. 2009; 5:3076-3085. [PubMed: 19433140]

Kanazawa I, Yamaguchi T, Yano S, et al. Adiponectin and AMP kinase activator stimulate proliferation, differentiation, and mineralization of osteoblastic MC3T3-E1 cells. BMC Cell Biology. 2007; 8:51. [PubMed: 18047638]

Kaplan, FS.; Hayes, WC.; Keaveny, TM., et al. Form and function of bone.. In: Simon, SP., editor. Orthopedic Basic Science. American Academy of Orthopedic Surgeons; Columbus, OH: 1994.

Kay S, Thapa A, Haberstroh KM, Webster TJ. Nanostructured polymer/nanophase ceramic composites enhance osteoblast and chondrocyte adhesion. Tissue Eng. 2002; 8:753-761. [PubMed: 12459054]

Kilpadi KL, Sawyer AA, Prince CW, et al. Primary human marrow stromal cells and Saos-2 osteosarcoma cells use different mechanisms to adhere to hydroxylapatite. J Biomed Mater Res A. 2004; 68:273-285. [PubMed: 14704969]

Kloss FR, Gassner R, Preiner J, et al. The role of oxygen termination of nanocrystalline diamond on immobilisation of BMP-2 and subsequent bone formation. Biomaterials. 2008a; 29:2433-2442. [PubMed: 18316119]

Kloss FR, Gassner R, Preiner J, et al. The role of oxygen termination of nanocrystalline diamond on immobilization of BMP-2 and subsequent bone formation. Biomaterials. 2008b; 29:2433-2442. [PubMed: 18316119]

Kobayashi S, Ohgoe Y, Ozeki K, et al. Dissolution effect and cytotoxicity of diamond-like carbon coatings on orthodontic archwires. J Mater Sci Mater Med. 2007; 18:2263-8. [PubMed: 17562139]

Konovalov VV, Melo A, Catledge SA, et al. Ultra-smooth nanostructured diamond films deposited from He/H2/CH4/N2 microwave plasmas. J Nanosci Nanotechnol. 2006; 6:258-61. [PubMed: 16573106]

Kopecek M, Bacakova L, Vacik J, et al. Improved adhesion, growth and maturation of human bonederived cells on nanocrystalline diamond films. Phys Stat Sol (a). 2008; 205:2146-2153.

Kurtz, S.; Lau, E.; Mowat, F., et al. The future burden of hip and knee revisions: U.S. projections from 2005 to 2030.. Paper presented at: 73rd Annual Meeting of the American Academy of Orthopaedic Surgeons; Chicago, IL. 2006;

Lappalainen R, Anttila A, Heinonen H. Diamond coated total hip replacements. Clin Orthop Relat Res. 1998:118-27. [PubMed: 9678039]

Lappalainen R, Selenius M, Anttila A, et al. Reduction of wear in total hip replacement prostheses by amorphous diamond coatings. Journal of Biomedical Materials Research Part B: Applied Biomaterials. 2003; 66B:410-413.

Lawson TR, Catledge SA, Vohra YK. Nanostructured Diamond Coated CoCrMo Alloys for Use in Biomedical Implants. Key Engineering Materials. 2005; 284-286:1015.

Lechleitner T, Klauser F, Seppi T, et al. The surface properties of nanocrystalline diamond and nanoparticulate diamond powder and their suitability as cell growth support surfaces. Biomaterials. 2008; 29:4275-4284. [PubMed: 18701160]

Lee S-T, Chen S, Agostinelli J, et al. Laser processing of carbon-implanted $\mathrm{Cu}, \mathrm{Ni}$, and Co crystals An attempt to grow diamond films. Applied Physics Letters. 1992; 60:2213-2215.

Lemons, J.; Louis, PJ.; Beck, P., et al. Biocompatibility of Nanostructured Diamond Surfaces for TMJ Articulation.. 32nd Annual Meeting and Exhibition of the AADR; San Antonio, TX. 2003. 
Lettington, A.; Steeds, JW. Thin Film Diamond. Chapman and Hall, London; New York: 1994.

Lombardi AV Jr. Mallory TH, Cuckler JM, et al. Mid-term results of a polyethylene-free metal-onmetal articulation. J Arthroplasty. 2004; 19:42-7. [PubMed: 15457417]

Lorenz HP. Investigation of TiN as an interlayer for diamond deposition on steel. Diamond and Related Materials. 1995; 4:1088-1092.

Maloney WJ, Smith RL. Periprosthetic osteolysis in total hip arthroplasty: The role of particulate wear debris. J Bone Joint Surg Am. 1995; 77:1448-1461.

Mayo M, Siegel RW, Liao YX, W.D. N. Nanoindentation of nanocrystalline ZnO. Journal of Materials Research. 1992; 7:973.

Mayo M, Siegel RW, Narayanasamy A, W.D. N. Mechanical properties of TiO2 as determined by nanoindentation. 1990; 5:1073.

McGovern TF, Moskal JT. Radiographic evaluation of periprosthetic metallosis after total knee arthroplasty. J South Orthop Assoc. 2002; 11:18-24. [PubMed: 12741582]

McKellop H, Park SH, Chiesa R, et al. In vivo wear of three types of metal on metal hip prostheses during two decades of use. Clin Orthop Relat Res. 1996:S128-40. [PubMed: 8769330]

Medley JB, Chan FW, Krygier JJ, Bobyn JD. Comparison of alloys and designs in a hip simulator study of metal on metal implants. Clin Orthop Relat Res. 1996:S148-59. [PubMed: 8769332]

Mercuri LG. The TMJ Concepts patient fitted Total Temporomandibular Joint Reconstruction Prosthesis in Total Temporomandibular Joint Reconstruction. Oral and Maxillofacial Surgery Clinics of North America. 2000a; 12:73-91.

Mercuri LG. The TMJ Concepts patient fitted Total Temporomandibular Joint Reconstruction Prosthesis in Total Temporomandibular Joint Reconstruction. Oral and Maxillofacial Surgery Clinics of North America. 2000b; 12:73-91.

Merkel KD, Erdmann JM, Mchugh KP, et al. Tumor necrosis factor-a mediates orthopedic implant osteolysis. Am J Pathol. 1999; 154:203-210. [PubMed: 9916934]

Mishra, A.; Davidson, J. Abrasion Resistance of candidate coatings for orthopedic articulating surfaces.. In: Doherty, P., et al., editors. Advances in Biomaterials. Elsevier Science publ.; Amsterdam, NL: 1992.

Moran CG, Tourret LJ. Recent Advances: Orthopaedics. BMJ. 2001; 322:902-5. [PubMed: 11302907]

Morshed MM, McNamara BP, Cameron DC, Hashmi MSJ. Effect of surface treatment on the adhesion of DLC film on 316L stainless steel. Surface and Coatings Technology. 2003; 163-164:541-545.

Narayan J, Godbole VP, White CW. Laser Method for Synthesis and Processing of Continuous Diamond Films on Nondiamond Substrates. Science. 1991; 252:416-418. [PubMed: 17740941]

Narayan RJ. Nanostructured diamondlike carbon thin films for medical applications. Materials Science and Engineering: C. 2005; 25:405-416.

National Institutes of Health. Total Hip Replacement. NIH Consensus Statement Online. 1994; 12(5): $1-31$.

Negrea G, Vermesan G. Investigations Of Diamond Layers Growth On Steel. Journal of Optoelectronics and Advanced Materials. 2000; 2:698-703.

Ohgoe Y, Kobayashi S, Ozeki K, et al. Reduction effect of nickel ion release on a diamond-like carbon film coated onto an orthodontic archwire. Thin solid films. 2006; 497:218-222.

Okumura M, Ohgushi H, Dohi Y, et al. Osteoblastic phenotype expression on the surface of hydroxyapatite ceramics. J Biomed Mater Res A. 1997; 37:122-9.

Pakes CI, Hoxley D, Rubanov S, et al. Work function of hydrogen terminated diamond surfaces under ion impact. Surf Sci. 2007; 601:5732-5.

Palin E, Liu H, Webster TJ. Mimicking the nanofeatures of bone increases bone-forming cell adhesion and proliferation. Nanotechnology. 2005; 16:1828-1835.

Papo MJ, Catledge SA, Vohra YK, Machado C. Mechanical wear behavior of nanocrystalline and multilayer diamond coatings on temporomandibular joint implants. J Mater Sci Mater Med. 2004; 15:773-7. [PubMed: 15387413]

Pareta R, Yang L, Kothari A, et al. Tailoring nanocrystalline diamond coated on titanium for osteoblast adhesion. J Biomed Mater Res A. 2010; 95:129-136. [PubMed: 20540097] 
Perry S. Interface characterization of chemically vapor deposited diamond on titanium and Ti?6Al?4V. J. Appl. Phys. 1993; 74:7542.

Piconi C, Maccauro G, Muratori F, et al. Ceramic Coatings in Metal-PE Joints: Where Are We Now? Bioceramics in Joint Arthroplasty. 2004 Steinkopff.

Polini R, Mantini FP, Braic M, et al. Effects of Ti- and Zr-based interlayer coatings on hot-filament chemical vapor deposition of diamond on high-speed steel. Journal of Materials Engineering and Performance. 2007; 15:201-207.

Polini R, Mattei G, Valle R, Casadei F. Raman spectroscopy characterization of diamond films on steel substrates with titanium carbide arc-plated interlayer. Thin Solid Films. 2006; 515:10111016.

Purdue PE, Koulouvaris P, Potter HG, et al. The cellular and molecular biology of periprosthetic osteolysis. Clin Orthop Relat Res. 2007; 454:251-261. [PubMed: 16980902]

Raffaini G, Ganazzoli F. Sequential adsorption of proteins and the surface modification of biomaterials: a molecular dynamics study. Journal of Materials Science: Materials in Medicine. 2007; 18:309-16. [PubMed: 17323163]

Revel PA. The combined role of wear particles, macrophages and lymphocytes in the loosening of total joint prostheses. J. Roy. Soc. Interface. 2008; 5:1263. [PubMed: 18647740]

Rezek, B.; Kratka, M.; Ukraintsev, E., et al. Diamond as functional material for bioelectronics and biotechnology.. In: Serra, PA., editor. Biosensors for Health, Environment and Biosecurity Intech. Open Access Publisher; 2011.

Roy RK, Lee KR. Biomedical applications of diamond-like carbon coatings: a review. J Biomed Mater Res B Appl Biomater. 2007; 83:72-84. [PubMed: 17285609]

Roy ME, Whiteside LA, et al. Diamond-like carbon coatings enhance scratch resistance of bearing surfaces for use in joint arthroplasty: Hard substrates outperform soft. Journal of Biomedical Materials Research Part B: Applied Biomaterials. 2009; 89B(2):527-535.

Rudnik V, Sanyal A, Syed FA, et al. Loss of ERE binding activity by estrogen receptor-alpha alters basal and estrogen-stimulated bone-related gene expression by osteoblastic cells. J Cell Biochem. 2008; 103:896-907. [PubMed: 17614350]

Saikko V, Ahlroos T, Calonius O, Keranen J. Wear simulation of total hip prostheses with polyethylene against $\mathrm{CoCr}$, alumina and diamond-like carbon. Biomaterials. 2001; 22:1507-14. [PubMed: 11374449]

Santavirta SS, Lappalainen R, et al. The Counterface, Surface Smoothness, Tolerances, and Coatings in Total Joint Prostheses. Clinical Orthopaedics and Related Research. 1999; 369:92-102. [PubMed: 10611864]

Scardi P, Leoni M, Cappuccio G, et al. Residual stress in polycrystalline diamond/Tî̀-,6Alî—,4V systems. Diamond and Related Materials. 1997; 6:807-811.

Schrand AM, Huang H, Cataleya C, et al. Are diamond nanoparticles cytotoxic? J Phy Chem B. 2007; 111:2-7.

Schwan J. Stress- induced formation of high-density amorphous carbon thin films. J. Appl. Phys. 1997; 82:6024.

Shenderova, OA.; Gruen, DM. Ultrananocrystalline Diamond: Synthesis, Properties, and Applications. William Andrew Publishing; Norwich/US: 2006.

Shimmin AJ, Back D. Femoral neck fractures following Birmingham hip resurfacing: a national review of 50 cases. J Bone Joint Surg Br. 2005; 87:463-4. [PubMed: 15795193]

Stevens MM, George JH. Exploring and engineering the cells surface interface. Science. 2005; 310:1135-1138. [PubMed: 16293749]

Taeger G, Podleska LE, et al. Comparison of Diamond-Like-Carbon and Alumina-Oxide articulating with Polyethylene in Total Hip Arthroplasty. Materialwissenschaft und Werkstofftechnik. 2003; 34(12):1094-1100.

Tamor, MA.; Vassell, WC. Raman fingerprinting of amorphous carbon films. AIP; 1994.

Tan J, Saltzman WM. Biomaterials with hierarchically defined micro- and nanoscale structure. Biomaterials. 2004; 25:3593-3601. [PubMed: 15020133] 
Tang L, Tsai C, Gerberich WW, Kruckeberg L, Kania DR. Biocompatibility of chemical vapourdeposited diamond. Biomaterials. 1995; 16:483-8. [PubMed: 7654876]

Terranova M. Structural investigation of the titanium/diamond film interface. J. Appl. Phys. 1996; 80:3552.

Thomas V, Dean DR, Vohra YK. Nanostructured biomaterials in regenerative medicine. Curr Nanosci. 2006; 2:155-177.

Thomas V, Halloran B, Catledge SA, et al. In vitro studies on the effect of particle-size on the macrophage cells responses to potential nanodiamond wear debris-particles. Acta Biomaterialia. 2011 (Under revision).

Toprani N, Catledge SA, Vohra YK, Thompson R. Interfacial adhesion and toughness of nanostructured diamond coatings. Journal of Materials Research. 2000; 15:1052-1055.

Treacy RB, McBryde CW, Pynsent PB. Birmingham hip resurfacing arthroplasty. A minimum followup of five years. J Bone Joint Surg Br. 2005; 87:167-70. [PubMed: 15736736]

Vandenbulcke L. Two-step process for improved diamond deposition on titanium alloys at moderate temperature. Appl. Phys. Lett. 1998; 72:501.

Vandrovcova M, Bakacova L. Adhesion, growth and differentiation of osteoblasts on surface modified materials developed for bone implants. Physiol. Res. 2011; 60:403-417. [PubMed: 21401307]

Vandrovcova, M.; Hanus, J.; Kylian, O., et al. Abstracts 2nd International Conference on Cellular and Molecular Bioengineering (ICCMB2). Singapore: 2010. Effect of different surface nanoroughness of $\mathrm{TiO} 2$ films on the growth of MG63 cells..

Vohra S, Hennessy KM, Sawyer AA, et al. Comparison of mesenchymal stem cell and osteosarcoma cell adhesion to hydroxyapatite. J Mater Sci Mater Med. 2008; 19:3567-3574. [PubMed: 18626747]

Wagner M, Wagner H. Medium-term results of a modern metal-on-metal system in total hip replacement. Clin Orthop Relat Res. 2000:123-33. [PubMed: 11039799]

Wang ML, Sharkey PF, Tuan RS. Particle bioreactivity and wear mediated osteolysis. J Arthroplasty. 2004; 19:1028-1038. [PubMed: 15586339]

Webster, TJ. Proteins: Structure and interactions patterns to solid surfaces.. In: Schwarz Ja, CC.; Putyera, K., editors. Encyclopedia of Nanoscience and Nanotechnology. Marcel Dekker; New York: 2004.

Webster TJ, Ejiofor JU. Increased osteoblast adhesion on nanophase metals: Ti, Ti6A14V, and CoCrMo. Biomaterials. 2004; 25:4731-4739. [PubMed: 15120519]

Webster TJ, Ergun C, Doremus RH, et al. Specific proteins mediate enhanced osteoblast adhesion on nanophase ceramics. J Biomed Mater Res A. 2000a; 51:475-483.

Webster TJ, Ergun C, Doremus RH, et al. Enhanced functions of osteoblasts on nanophase ceramics. Biomaterials. 2000b; 21:1803-1810. [PubMed: 10905463]

Webster TJ, Siegal RW, Bizios R. Osteoblast adhesion on nanophase ceramics. Biomaterials. 1990; 20:1221-1227. [PubMed: 10395391]

Webster TJ, Smith TA. Increased osteoblast function on PLGA composites containing nanophase titania. J Biomed Mater Res A. 2005; 74:677-686. [PubMed: 16035065]

Wei Q, Yu Z, Ma L, Yin D. Enhanced Nucleation and Smoothness of Nanocrystalline Diamond Films via W-C Gradient Interlayer. International Journal of Modern Physics B. 2009; 23:1676-1682.

Wright, T.; Sculco, TP.; Su, EP., et al. Joint Replacement: Implant Bearing Surface Materials. New York: 2009.

Wroblewski BM. Professor Sir John Charnley (1911-1982). Rheumatology (Oxford). 2002; 41:824-5. [PubMed: 12096235]

Xu T, Pruitt L. Diamond-like carbon coatings for orthopaedic applications: an evaluation of tribological performance. Journal of Materials Science: Materials in Medicine. 1999; 10:83-90. [PubMed: 15347929]

Yang L, Sheldon BW, Webster TJ. The impact of diamond nanocrystallinity on osteoblast functions. Biomaterials. 2009a; 30:3458-3465. [PubMed: 19339049] 
Yang L, Sheldon BW, Webster TJ. Orthopedic diamond coating: control of surface properties and their impact on osteoblast adhesion and proliferation. J Biomed Mater Res A. 2009b; 91:548-556. [PubMed: 18985788]

Zhao G, Raines AL, Wieland M, et al. Requirement for both micron- and submicron scale structure for synergistic responses of osteoblasts to substrate surface energy and topography. Biomaterials. 2007; 28:2821-2829. [PubMed: 17368532]

Zuo D, Li XF, Wang M, et al. Adhesion improvement of CVD diamond film by introducing an electro-deposited interlayer. J. Mat. Proc. Technol. 2003; 138:455. 

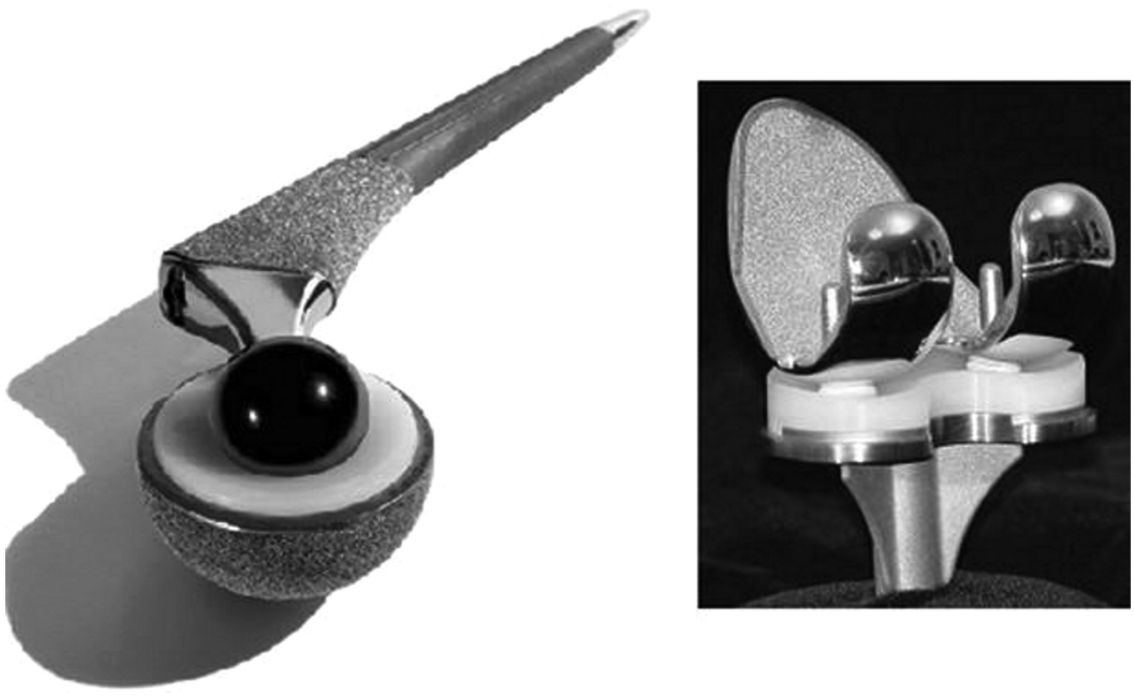

5.1.

Examples of total hip and knee replacement devices used in industry. Both devices shown here have femoral head components with a ceramic surface layer (oxidized zirconium on left, titanium nitride on right). These devices also use a polyethylene liner. 
Schematic showing formation of diamond composite

i) Deposition of first layer of buffer material

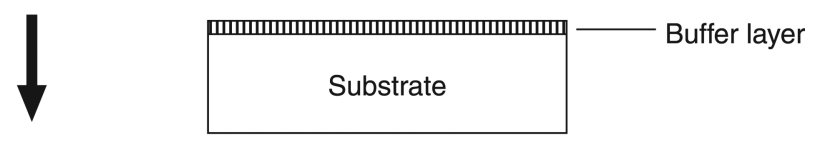

ii) Synthesis of isolated diamond crystallites

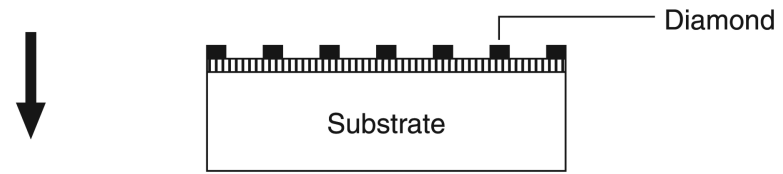

iii) Sequential depositions

(Random interconnections of diamond particles)
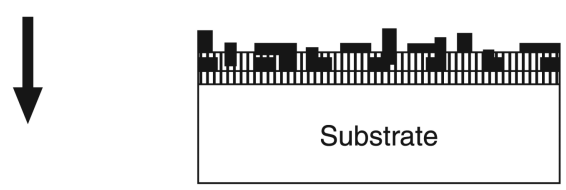

iv) Deposition of top continuous diamond layer

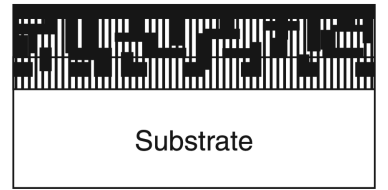

5.2.

Schematic showing different stages of the formation of diamond composites for deposition on cobalt-chromium substrate. Reprinted from Materials Science and Engineering B, 58, Godbole, V. P., Narayan, R., Xu, Z., Narayan, J. and Sankar, J., Diamond films and composites on cobalt-chromium alloys, 254, Copyright (1999), with permission from Elsevier. 


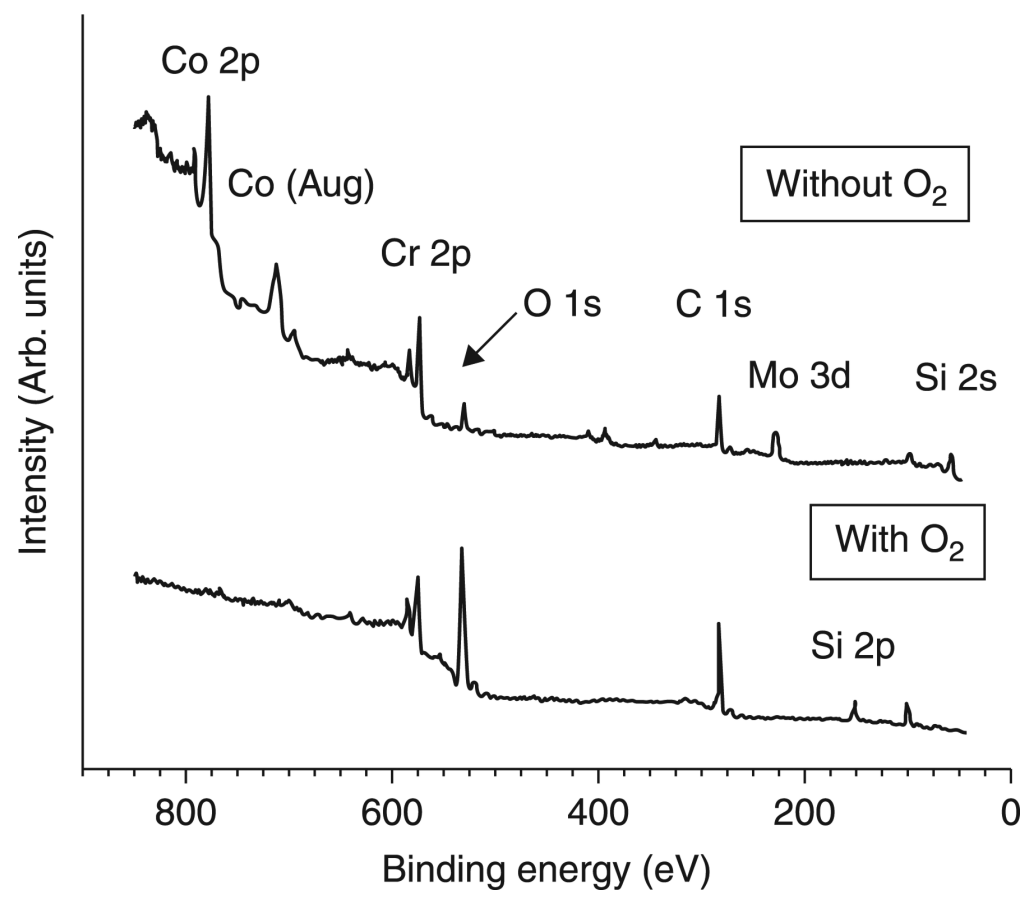

5.3 .

XPS survey spectra after nucleation of nanostructured diamond films grown on CoCrMo with and without oxygen at $\mathrm{T}_{\text {sub }}=915^{\circ} \mathrm{C}$. When oxygen is used, no cobalt or molybdenum is detected on the surface, although chromium is still present. Reprinted with kind permission from Springer Science + Business Media: Journal of Materials Science: Materials in Medicine, Improved adhesion of ultra-hard carbon films on cobalt-chromium orthopaedic implant alloy, 22, 2011, Catledge, S. A., Vaid, R., Diggins, P. T., Weimer, J. J., Koopman, M. and Vohra, Y. K., Figure Number 6. 

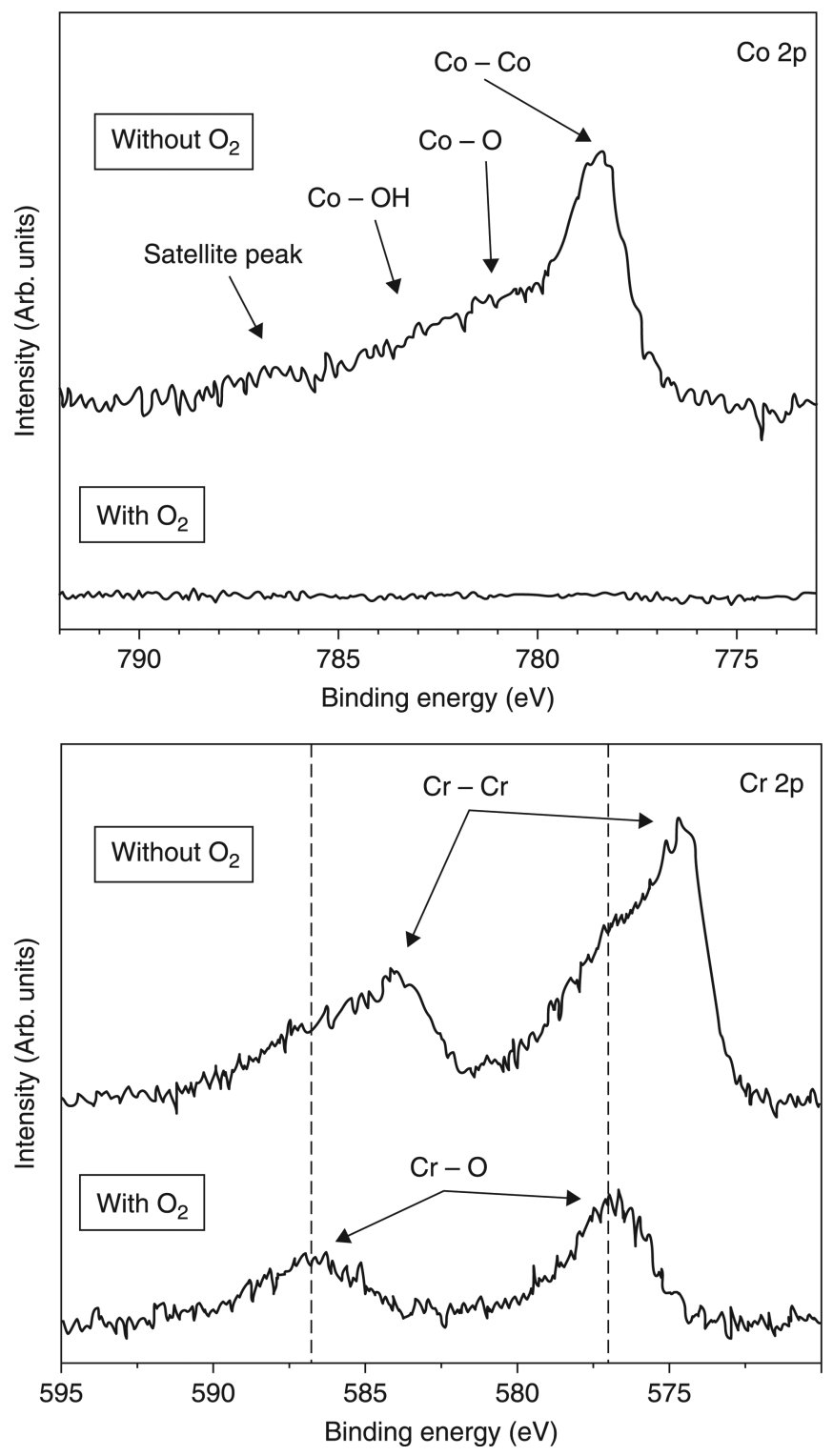

5.4.

High resolution XPS spectra for Co $2 p$ and $\mathrm{Cr} 2 \mathrm{p}$ after nucleation of nanostructured diamond films grown on CoCrMo with and without oxygen at $\mathrm{T}_{\mathrm{sub}}=915^{\circ} \mathrm{C}$. When oxygen is not used, chromium is detected primarily in elemental form, whereas it is primarily bonded with oxygen when oxygen is used in the feedgas. Reprinted with kind permission from Springer Science + Business Media: Journal of Materials Science: Materials in Medicine, Improved adhesion of ultra-hard carbon films on cobalt-chromium orthopaedic implant alloy, 22, 2011, Catledge, S. A, Vaid, R., Diggins, P. T., Weimer, J. J., Koopman, M. and Vohra, Y. K., Figure Number 7. 

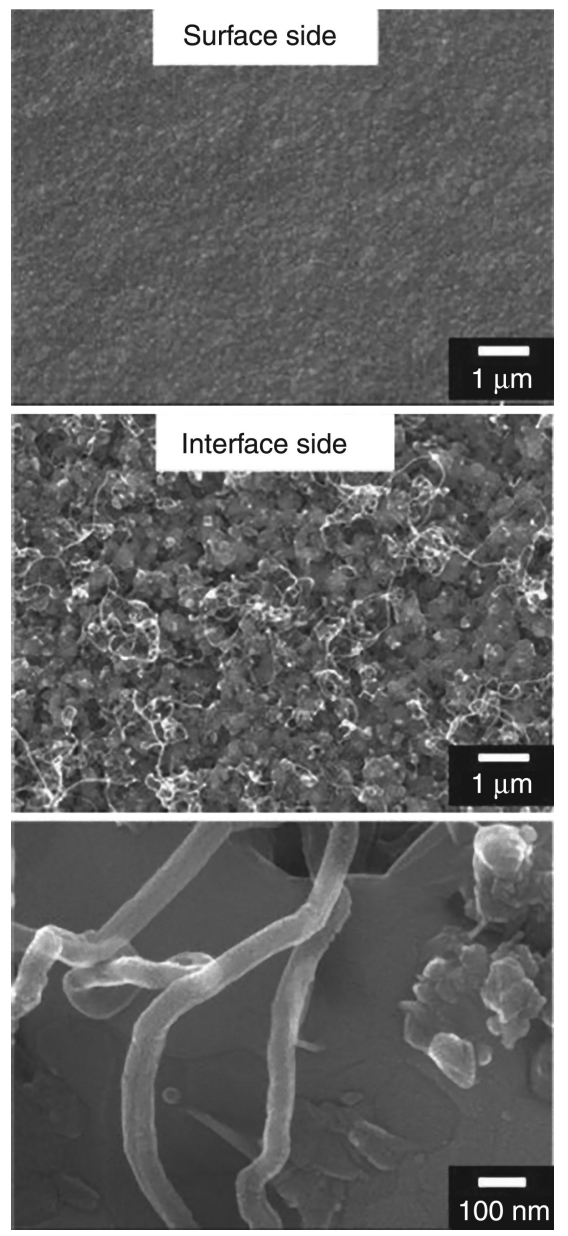

5.5.

SEM images showing surface (top) and interface (middle and bottom) morphology from a delaminated nanostructured diamond film grown on CoCrMo with oxygen at a low substrate temperature $\left(825^{\circ} \mathrm{C}\right)$. Carbon nanotubes are observed to develop at the interface. Reprinted with kind permission from Springer Science + Business Media: Journal of Materials Science: Materials in Medicine, Improved adhesion of ultra-hard carbon films on cobaltchromium orthopaedic implant alloy, 22, 2011, Catledge, S. A, Vaid, R., Diggins, P. T., Weimer, J. J., Koopman, M. and Vohra, Y. K., Figure Number 5. 


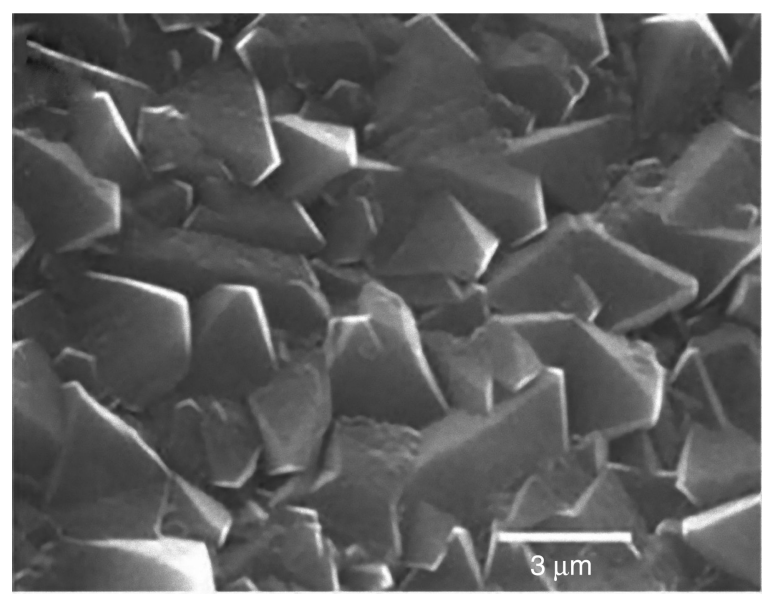

(a)

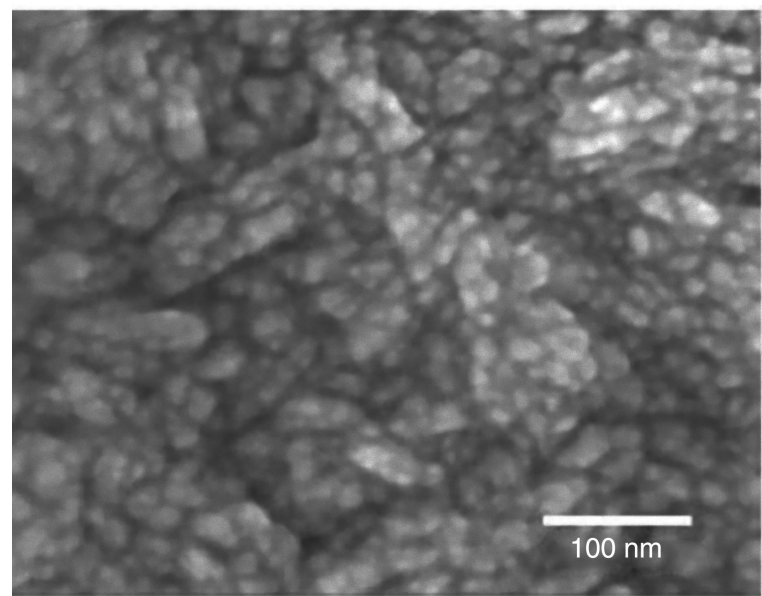

(b)

5.6.

SEM images showing CVD diamond films grown (a) without $\mathrm{N}_{2}$ and (b) with $\mathrm{N}_{2}$ feedgas addition to a $\mathrm{H}_{2}+\mathrm{CH}_{4}$ plasma consisting of $15 \%$ vol $\mathrm{CH}_{4}$. Note the difference in scale bars. 


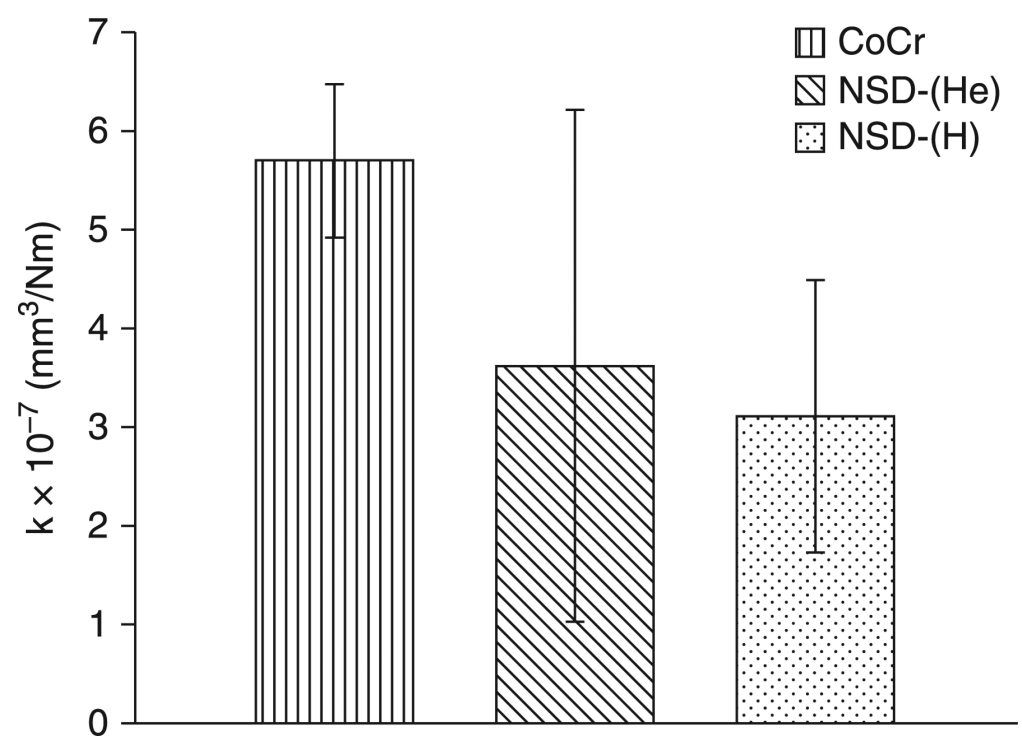

5.7 .

Average wear factor for polyethylene on CoCr, NSD-(He) and NSD-(H). Error bars represent one standard deviation. Reprinted with permission from Journal of Biomedical Materials Research B: Applied Biomaterials, Preliminary tribological evaluation of nanostructured diamond coatings against ultra-high molecular weight polyethylene, 85, 2008, Hill, M. R., Catledge, S. A, Konovalov, V., Clem, W. C., Chowdhury, S. A, Etheridge, B. S., Stanishevsky, A, Lemons, J. E., Vohra, Y. K. and Eberhardt, A W., Copyright @ 2007 Wiley Periodicals, Inc. 


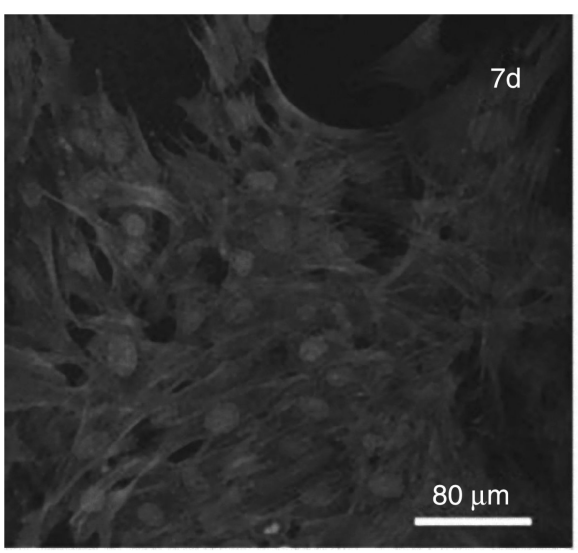

(a)

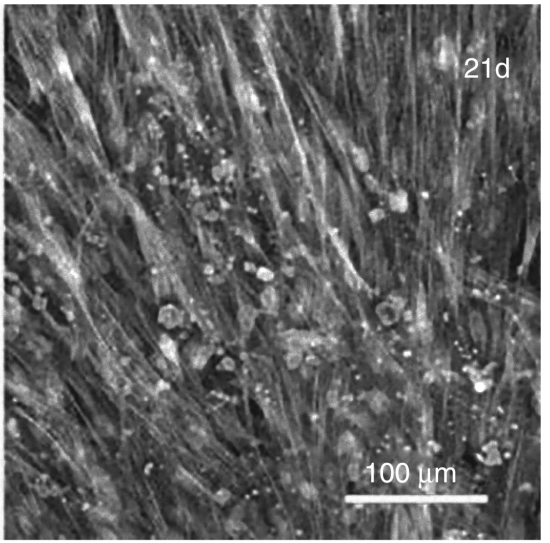

(b)

5.8.

CLSM observation of human bone marrow osteoblastic cells cultured on NCD films at days 7 (a) and 21 (b) (calcein, phalloidin and propidium iodide labelling). Reprinted with permission from Journal of Biomedical Materials Research, Nanocrystalline diamond: In vitro biocompatibility assessment by MG 63 and human bone marrow cells cultures, 87A, 2008, Amaral, M., Dias, A G., Gomes, P. S., Lopes, M. A, Silva, R. F. and Santos, J. D. Copyright @ 2008 Wiley Periodicals, Inc. 


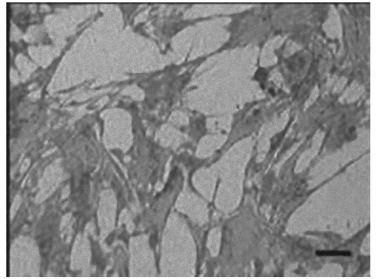

(a)

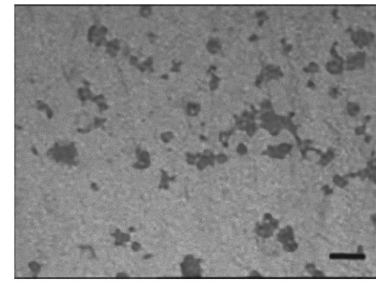

(b)

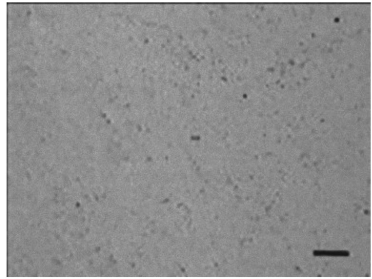

(c)

5.9.

Reflected light microscopy images demonstrating the morphology of MSCs cultured in serum-free DMEM for 1 hour on (a) H-terminated USND, (b) O-terminated USND and (c) F-terminated USND. The cells readily attach to the H-terminated surface, whereas adhesion is very weak to the O-terminated or F-terminated surfaces. Scale bar $=100 \mu \mathrm{m}$. Clem et al. Biomaterials 29 (2008) 3461-3468 @ Elsevier 2008. 


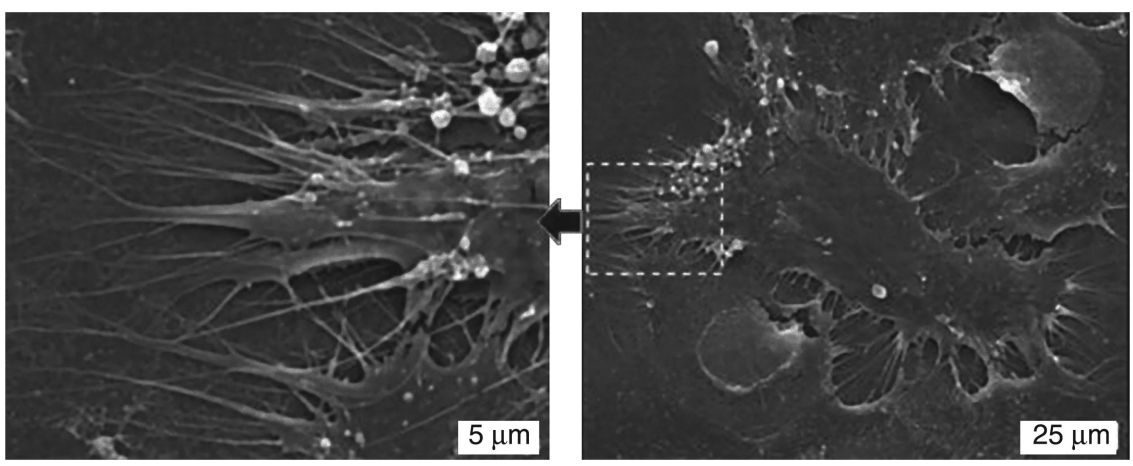

5.10 .

SEM images of MSCs cultured for 24 hours on H-terminated USND. The image on the left shows a higher magnification of the area indicated in the right image. The cells adopt a spread morphology and extend many pseudopodia along the surface. Reprinted with permission from Clem et al. Biomaterials 29 (2008) 3461-3468 @) Elsevier 2008. 


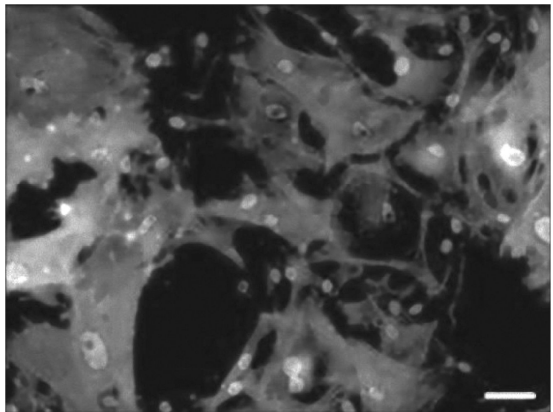

(a)

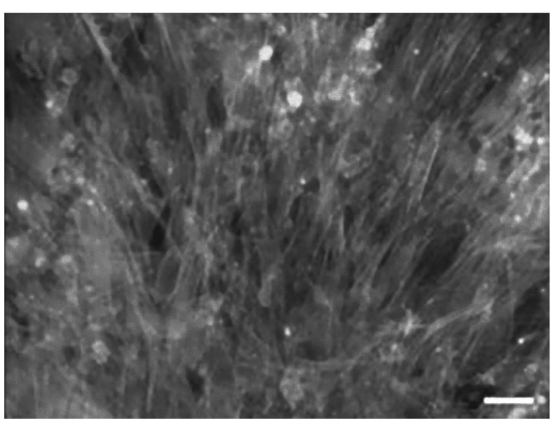

(c)

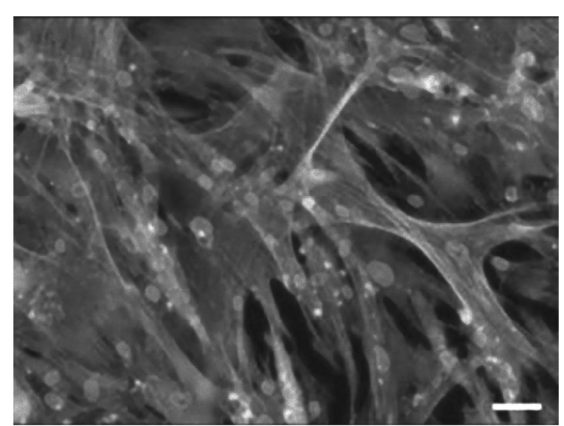

(b)

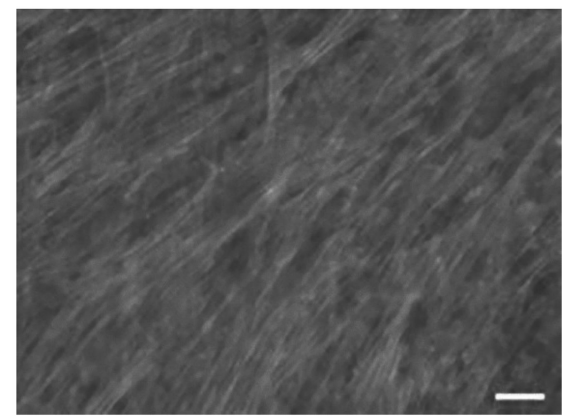

(d)

5.11.

Fluorescent images showing morphology of MSCs cultured for up to 2 weeks on Hterminated USND coatings. The cells were cultured on a USND surface for (a) 3 hours, (b) 24 hours, (c) 7 days, and (d) 14 days. MSCs readily attach, spread, and eventually form a confluent layer on this surface. Scale bar $=50 \mu \mathrm{m}$. Reprinted with permission from Clem et al. Biomaterials 29 (2008) 3461-3468 (C) Elsevier 2008. 
(a)

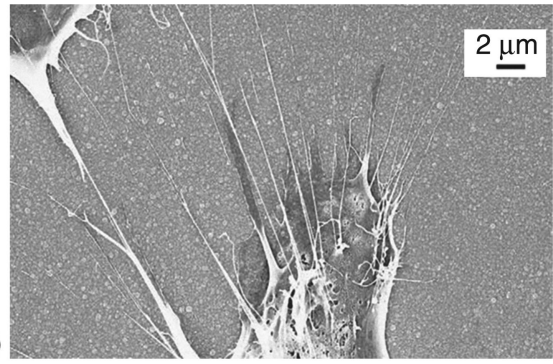

(b)

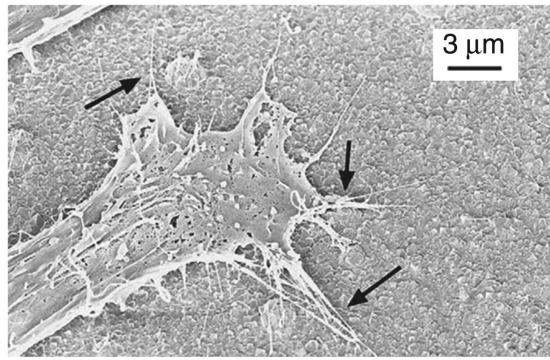

(c)

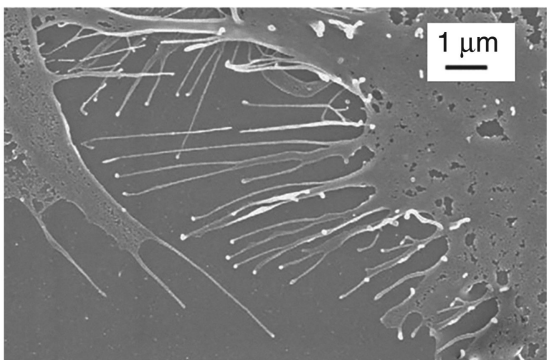

5.12 .

Osteoblast filopodia extensions on $\mathrm{NCO}$ (a), SMCD (b) and Si (c) after $48 \mathrm{~h}$ of culture. The arrows in (b) indicate filopodia extensions converging to some spots on the diamond surfaces. Osteoblast seeding density was 10,000 cells $/ \mathrm{cm}^{2}$. Reprinted from Biomaterials, 30, Yang, L., Sheldon, B. W. and Webster, T. J., The impact of diamond nanocrystallinity on osteoblast functions, 3463, Copyright (2009), with permission from Elsevier. 


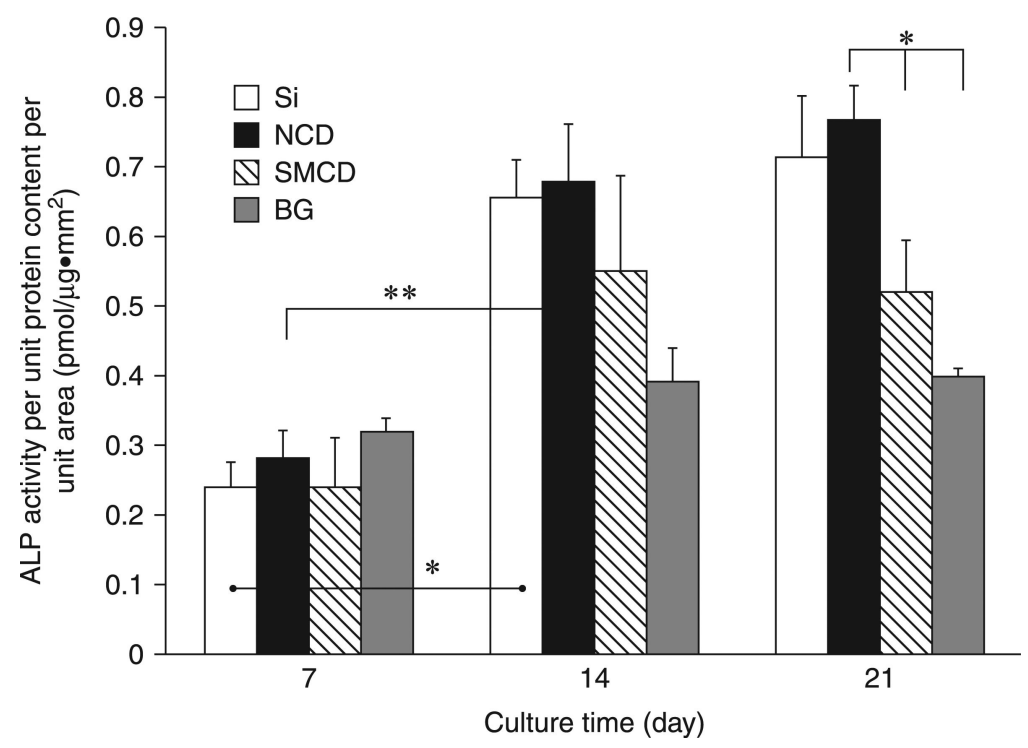

5.13.

Alkaline phosphatase (ALP) activity of osteoblasts on NCD, SMCD, Si and borosilicate glass (BG) after 7, 14 and 21 days. Data were expressed as mean \pm standard deviation of the mean $(\mathrm{n}=9)$. ${ }^{*} \mathrm{p}<0.01$ and ${ }^{* *} \mathrm{p}<0.05$. Osteoblast seeding density was $100,000 \mathrm{cells} / \mathrm{cm}^{2}$. Reprinted from Biomaterials, 30, Yang, L., Sheldon, B. W. and Webster, T. J., The impact of diamond nanocrystallinity on osteoblast functions, 3463, Copyright (2009), with permission from Elsevier. 


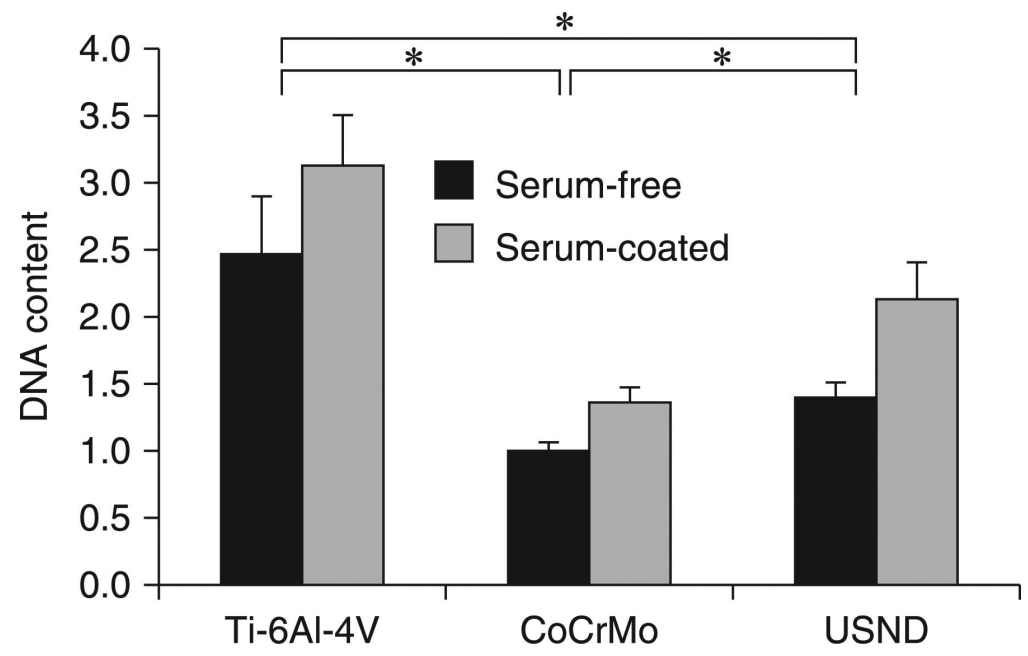

5.14.

Quantitative analysis of MSC adhesion to H-terminated USND, Ti-6AI-4V and CoCrMo. Prior to cell seeding, the surfaces were either pre-coated with serum (FBS) or left uncoated. Cells were cultured for 90 minutes, followed by mechanical agitation to remove loosely bound MSCs. Remaining attached cells were quantified by assay for DNA content. Adhesion of MSCs to USND was found to be intermediate between that of Ti-6AI-4V and $\mathrm{CoCrMo}$, in both serum-free conditions and in the presence of serum. * denotes $\mathrm{p}<0.05$. Reprinted with permission from Clem et al., Biomaterials 29 (2008) 3461-3468 @ Elsevier 2008. 


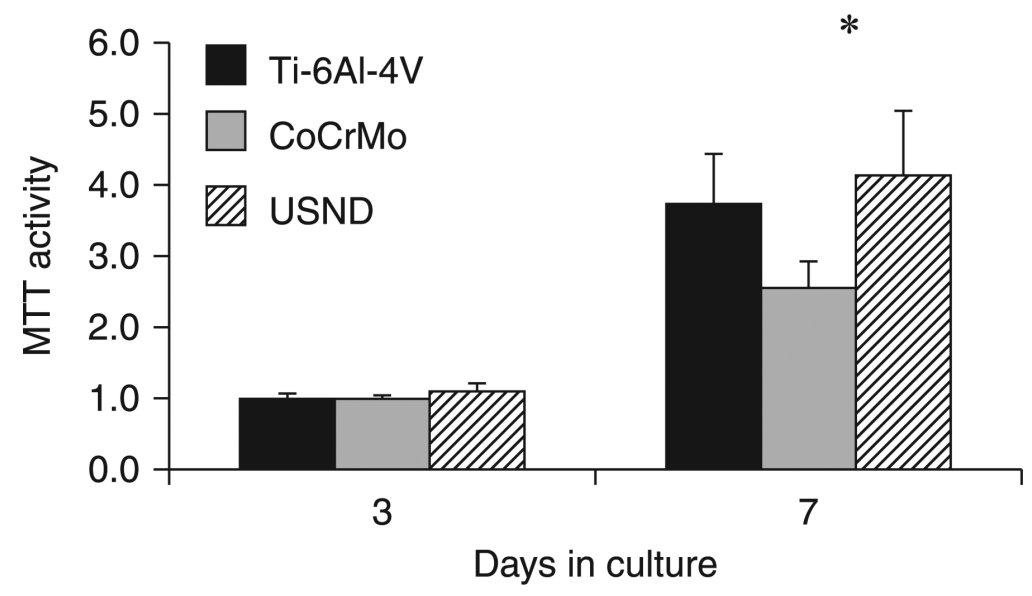

5.15.

Proliferation assay to assess potential long-term effects of exposure to USND on cell behaviour. A small number of MSCs were seeded onto H-terminated USND, Ti-6AI-4V, or CoCrMo and cultured for up to 1 week. The number of viable cells was quantified at days 3 and 7 by an MTT assay. Cell proliferation on USND was not significantly different from Ti-6AI-4V, but was greater than that observed for cells grown on CoCrMo. * denotes $\mathrm{p}<$ 0.05. Reprinted with permission from Clem et al., Biomaterials 29 (2008) 3461-3468 @) Elsevier 2008. 


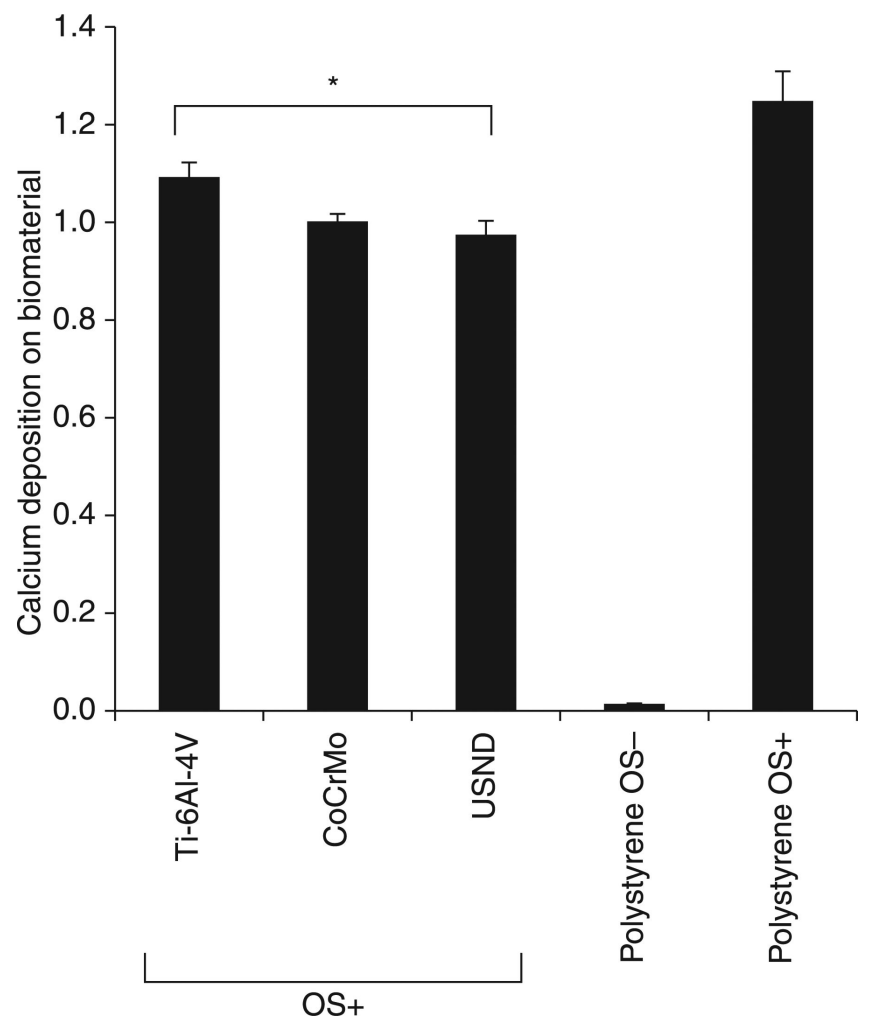

5.16.

Analysis of mineralized matrix deposited on H-terminated USND, Ti-6AI-4V and CoCrMo. Osteoblastic differentiation of MSCs adherent to the metal substrates was induced by culture for 4 weeks in an osteogenic medium (OSp). The cells were allowed to deposit mineral on the biomaterial surfaces, and then the calcium content was quantified at week 4 . Cells were also cultured on tissue culture plastic in osteogenic media (OSp, positive control) or in normal growth media (OS negative control). Slightly more mineral was deposited on Ti-6AI-4V than USND, but the difference in mineral deposition between USND and CoCrMo surfaces was not significant. * denotes $\mathrm{p}<0.05$. 


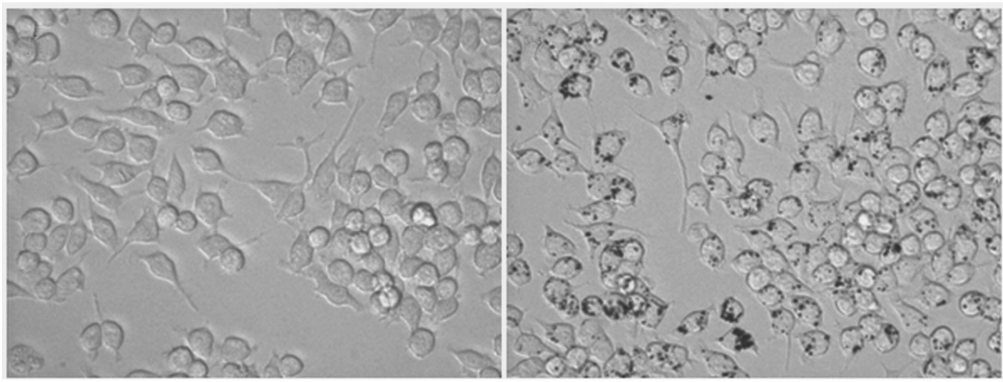

(a)

(b)

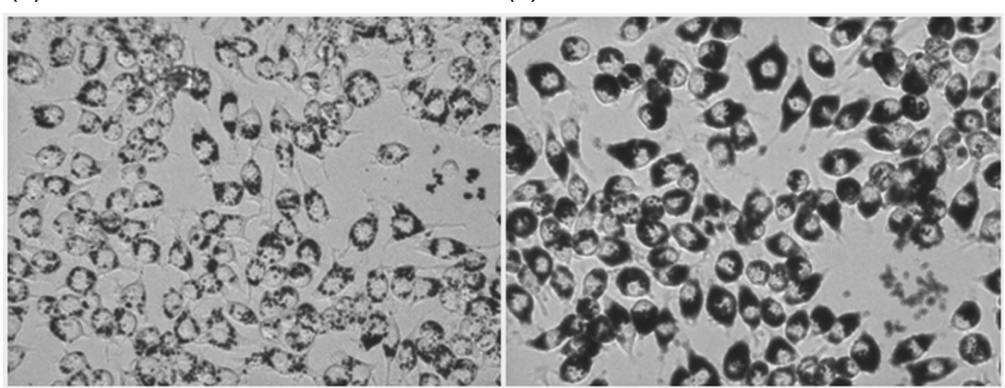

(c)

(d)

5.17 .

Optical micrographs $(400 \times)$ of free-floating nanodiamond particles $(2-10 \mathrm{~nm})$ of varying concentrations cultured with macrophage cells for 24 hours; macrophage cells without diamond particles (a) and cells with diamond particles of $10 \mu \mathrm{g} / \mathrm{mL}$ (b), $100 \mu \mathrm{g} / \mathrm{mL}$ (c), and $200 \mu \mathrm{g} / \mathrm{mL}$ (d). 

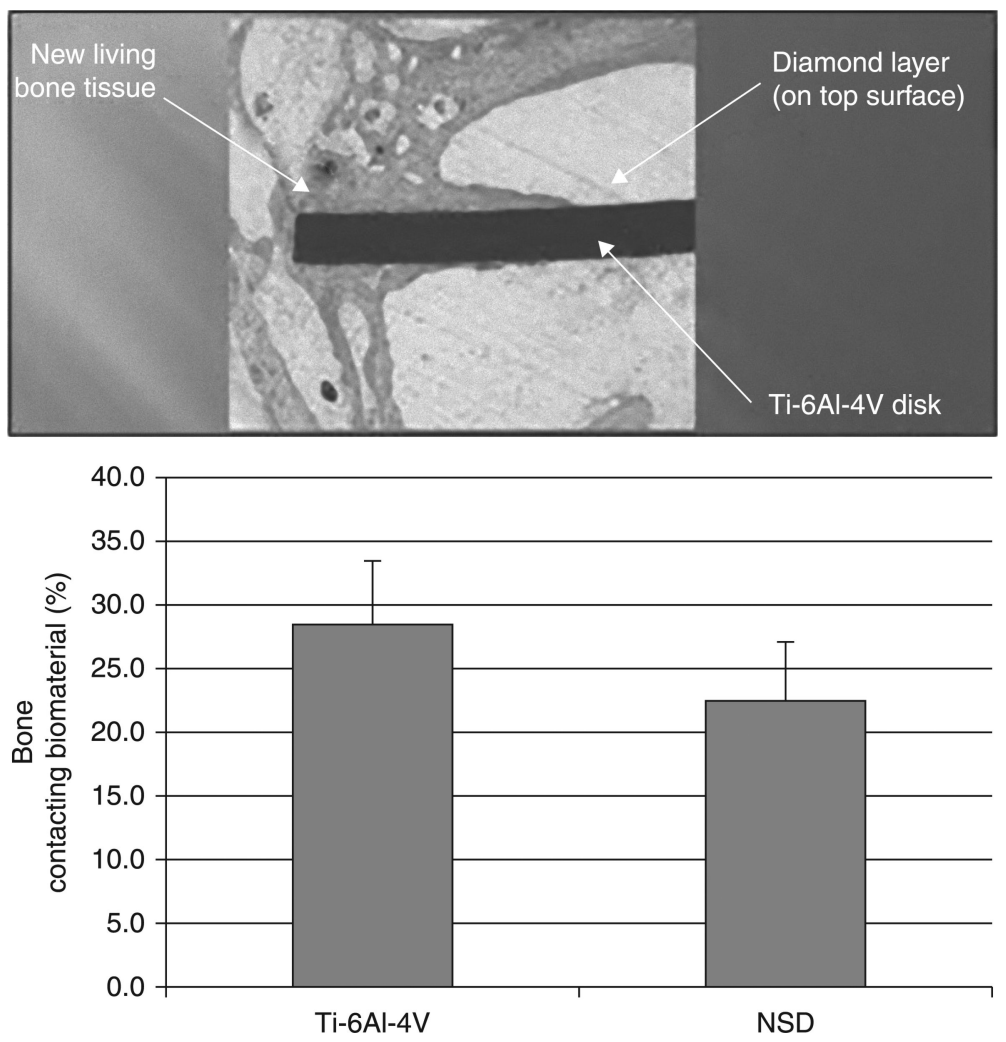

5.18 .

Results of in vivo studies for NSD-coated Ti-6AI-4V disc implanted into the leg bone of New Zealand white rabbits showing comparable bone coverage against uncoated Ti-6AI-4V control (top) and showing excellent biocompatibility (bottom). 